\title{
Factors contributing to anaemia after uncomplicated falciparum malaria in under five year-old Nigerian children ten years following adoption of artemisinin-based combination therapies as first-line antimalarials
}

Akintunde Sowunmi ${ }^{1,2,3,20^{*}}$, Bayo Fatunmbi ${ }^{1,4}$, Kazeem Akano ${ }^{2}$, Olubunmi A. Wewe ${ }^{2}$, Chimere Agomo 1,5, Finomo Finomo ${ }^{1,6}$, Joy Ebenebe ${ }^{1,7}$, Nma Jiya ${ }^{1,8}$, Jose Ambe ${ }^{1,9}$, Robinson Wammanda, ${ }^{1,10}$, Godwin Ntadom ${ }^{1,2}$, Olugbenga Mokuolu, 1,11, George Emechebe ${ }^{1,12}$, Nnenna Ezeigwe ${ }^{1}$, Adejumoke I. Ayede ${ }^{13}$, Elsie O. Adewoye ${ }^{14}$, Grace O. Gbotosho ${ }^{2,3,15}$, Onikepe A. Folarin ${ }^{16}$, Christian T. Happi ${ }^{1,16}$, Stephen Oguche ${ }^{1,17}$, Wellington A. Oyibo ${ }^{1,18}$ and Francis Useh ${ }^{1,19}$

\begin{abstract}
Background: Artemisinin-based combination therapies (ACTs) have remained efficacious treatments of acute falciparum malaria in many endemic areas but there is little evaluation of factors contributing to the anaemia of acute falciparum malaria following long term adoption of ACTs as first-line antimalarials in African children.

Methods: Malarious $<5$ year-olds randomized to artemether-lumefantrine, artesunate-amodiaquine or dihydroartemisininpiperaquine treatments were followed up clinically for 6 weeks. Anaemia was defined as haematocrit <30\%; Malariaattributable fall in haematocrit (MAFH) as the difference between haematocrit 28-42 days post- and pre-treatment; Total MAFH (TMAFH) as the difference between days 28-42 haematocrit and the lowest haematocrit recorded in the first week post-treatment initiation; Drug-attributable fall in haematocrit (DAFH) as the difference between MAFH and TMAFH; Early appearing anaemia (EAA) as haematocrit <30\% occurring within 1 week in children with normal haematocrit pre-treatment. Predictors of anaemia pre-treatment, EAA, MAFH or DAFH $>4 \%$ were evaluated by stepwise multiple logistic regression models. Survival analysis and kinetics of DAFH were evaluated by Kaplan-Meier estimator and non-compartment model, respectively.

(Continued on next page)
\end{abstract}

\footnotetext{
* Correspondence: akinsowunmi@hotmail.com

${ }^{1}$ Antimalarial Therapeutic Efficacy Monitoring Group, National Malaria

Elimination Programme, The Federal Ministry of Health, Abuja, Nigeria

2Department of Pharmacology and Therapeutics, University of Ibadan,

Ibadan, Nigeria

Full list of author information is available at the end of the article
} 
(Continued from previous page)

Results: Pre-treatment, 355 of 959 children were anaemic. Duration of illness $>2$ days and parasitaemia $\leq 10,000 \mu L^{-1}$ were independent predictors of anaemia pre-treatment. EAA occurred in 301 of 604 children. Predictors of EAA were age $\leq 15$ months, history of fever pre-treatment and enrolment haematocrit $\leq 35 \%$. The probabilities of progression from normal haematocrit to EAA were similar for all treatments. MAFH >4\% occurred in 446 of 694 children; its predictors were anaemia pre-treatment, enrolment parasitaemia $\leq 50,000 \mathrm{LL}^{-1}$, parasitaemia one day post-treatment initiation and gametocytaemia. DAFH >4\% occurred in 334 of 719 children; its predictors were history of fever pre-and fever 1 day post-treatment initiation, haematocrit $\geq 37 \%$, and parasitaemia $>100,000 \mathrm{uL}^{-1}$. In 432 children, declines in DAFH deficits were monoexponential with overall estimated half-time of $2.2 \mathrm{~d}$ (95\% Cl 1.9-2.6). Area under curve of deficits in DAFH versus time and estimated half-time were significantly higher in non-anaemic children indicating greater loss of haematocrit in these children.

Conclusion: After ten years of adoption of ACTs, anaemia is common pre-and early post-treatment, falls in haematocrit attributable to a single infection is high, and DAFH $>4 \%$ is common and significantly lower in anaemic compared to non-anaemic Nigerian children.

Trial registration: Pan African Clinical Trial Registry (PACTR) [PACTR201709002064150, 1 March 2017].

Keywords: Plasmodium falciparum malaria-associated anaemia, Artemisinin-based combination treatments, Children, Nigeria

\section{Background}

Artemisinin-based combination therapies (ACTs) have been adopted as first-line treatments of uncomplicated Plasmodium falciparum malaria by over 80 countries [1-3]. In many of these countries particularly those in southeast Asia, the period of adoption as first-line treatments has exceeded 10 years $[4,5]$. In Nigeria, artemetherlumefantrine $(\mathrm{AL})$ and artesunate-amodiaquine (AA) were adopted as first-line treatments in 2005 [6].

Anaemia, a consequence of treated and untreated falciparum malaria, is common before, during or after treatment in up to $40 \%$ of African children [7-9]. It is a major public health problem, and in anaemic patients, has been attributed to repeated infections within a short time frame, bone marrow dyserythropoiesis and increased splenic clearance of infected and non-infected erythrocytes [10-13]. Anaemia can also occur in African children with apparently asymptomatic infections $[14,15]$.

Despite adoption as first-line treatments in many countries for over a decade, there is little evaluation of the predictors of anaemia before, during or in the 1 week following initiation of treatment in malarious children. In malarious patients, the effects of infections and the drugs used to treat the infections can be evaluated using the following indices: malaria-attributable fall in haematocrit (MAFH), total malaria-attributable fall in haematocrit (TMAFH) [10], or drug-attributable fall in haematocrit (DAFH) [16]. Such evaluations are urgently needed as they can provide useful leads in the diagnosis and management of the anaemia following ACTs, and the extent to which adoption of ACTs as first-line antimalarials has modified the burden of the anaemia associated with malaria infections. From the clinical point of view, worsening of haematocrit levels or falls in haematocrit following ACTs of uncomplicated falciparum malaria in young African children, until proven otherwise, can be considered an adverse event attributable to the $\operatorname{drug}(\mathrm{s})$ used [17] - drug attributable falls in haematocrit [16]. However, DAFH can be attributed to interaction between the drug, the infection and the host.

For the reasons indicated above, the aims of present study were: using pre-determined cut-offs (haematocrit $<30 \%$, MAFH or DAFH $>4 \%$ ), to evaluate the predictors of the following: anaemia at presentation, progression from normal haematocrit at presentation to anaemia within 1 week of starting treatment (early-appearing anaemia [EAA]), and MAFH or DAFH $>4 \%$ in a group of under 5 year old malarious children who were treated with AL, AA or dihydroartemisinin-piperaquine (DHP), during an open labelled therapeutic efficacy study. An additional aim was to evaluate the kinetics of the disposition of DAFH in anaemic and non-anaemic children following initiation of treatment.

\section{Methods \\ Study locations}

The study took place between June 2014 and September 2015. It was part of a programme to monitor antimalarial therapeutic efficacy at eight sentinel sites located in six geographical areas of Nigeria namely, Ogbia, Neni, Ogwa, Numan, Ilorin, Kura, Bodinga and Ibadan in Bayelsa, Anambra, Imo, Adamawa, Kwara, Kano, Sokoto and Oyo States, respectively. In virtually all study locations, malaria is hyperendemic and transmission occurs all year round; however, it is more intense during the rainy season from April to October. The details of the therapeutic efficacy study will be described elsewhere. The dataset presented here have not been previously published elsewhere. 


\section{Study procedures}

Standardized procedures and protocol were used at all sentinel sites. Briefly, patients were eligible to participate in the study if they were: aged 6-59 months, had symptoms compatible with acute uncomplicated malaria and $P$. falciparum mono-infections between 2000 and $200,000 \mu \mathrm{L}^{-1}$ of blood, no history of antimalarial drug ingestion in the two weeks preceding enrolment, had no evidence of severe malaria $[18,19]$ and parents or guardians gave written informed consent.

Enrolled patients were randomized to AL, AA or DHP treatments for 3 days (day $0-2$ ) as previously described [20]. The day of presentation (day of starting treatment) was regarded as day 0 . Thick and thin blood films were obtained from each child as soon as they came to the clinic and the slides were carefully labelled with the patients' codes and air-dried before being Giemsa-stained. Follow-up with clinical and parasitological evaluation was done daily on days 1-3 and 7, and thereafter, weekly for additional 5 weeks. Parasitaemia, asexual or sexual, in thick films was estimated by counting asexual and sexual parasites relative to 500 leukocytes, or 500 asexual or sexual forms whichever occurred first. From this figure, the parasite density was calculated assuming a leukocyte count of $6000 \mu \mathrm{L}^{-1}$ of blood [21]. A slide was considered asexual parasite negative if no asexual parasite was detected after examination of 200 microscope fields. Parasite reduction ratio was defined as previously described [22].

\section{Haematological evaluation}

Capillary blood obtained from a finger prick was collected before treatment and during follow-up, and was used to measure haematocrit using a microhaematocrit tube and microcentrifuge (Hawksley, Lancing, UK). Anaemia was defined as a haematocrit $<30 \%$ and was further classified as mild, moderate or severe if haematocrit was $21-29 \%, 15-20 \%$ or $<15 \%$, respectively $[8,10]$.

\section{Definition of haematological parameters evaluated}

The following parameters described by Price et al. [10] and modified by Sowunmi et al. [16] were used for evaluation (Fig. 1):

(i) Malaria-attributable fall in haematocrit (MAFH) before treatment was defined as the difference between the patient's maximum haematocrit value measured on days $28-42$ and that on day 0 (pre-treatment).

(ii) Total malaria-attributable fall in haematocrit (TMAFH) was defined as the difference between the patient's maximum haematocrit on days 28-42 and lowest haematocrit value recorded in the first week post-treatment initiation.

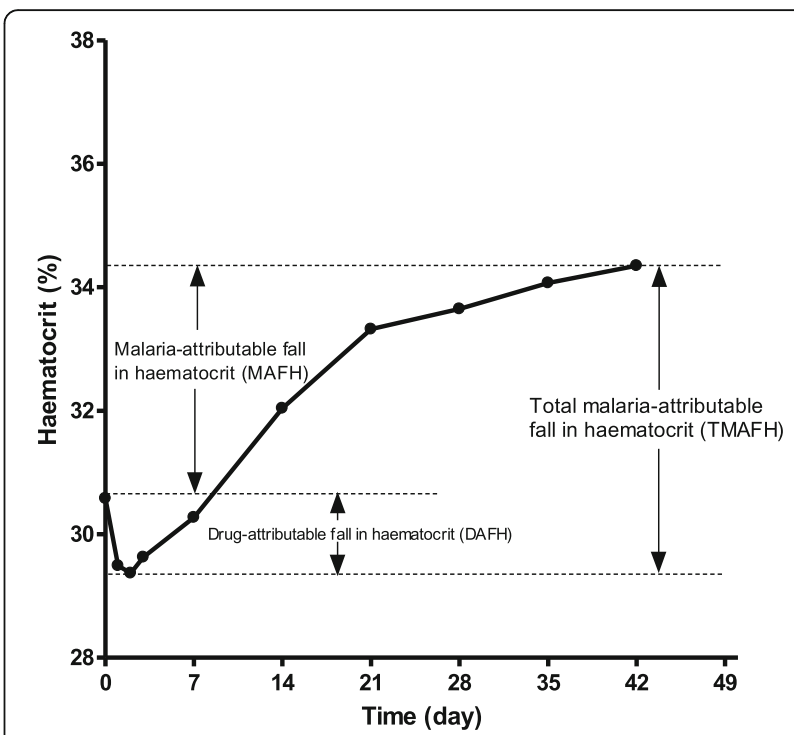

Fig. 1 Parameters used for estimation of malaria-related falls in haematocrit (adapted from Price et al. [10] and Sowunmi et al. [16]

(iii)Drug-attributable falls in haematocrit (DAFH) was defined as the difference between MAFH and TMAFH, or as the difference between pre-treatment haematocrit and the lowest haematocrit recorded in the first week post-treatment initiation.

(iv)Early-appearing anaemia (EAA) was defined as haematocrit $<30 \%$ occurring within 1 week in patients who were non-anaemic pre-treatment.

(v) Anaemia recovery time: Anaemia recovery time (in anaemic children pre-treatment) was defined as time elapsing from initiation of treatment to attainment of haematocrit value $\geq 30 \%$. In non-anaemic children (pre-treatment) who subsequently progressed to anaemia following initiation of treatment (early-appearing anaemia), anaemia recovery time was defined as the time from the appearance of (onset of anaemia), to recovery from anaemia (until haematocrit rose to $\geq 30 \%$ ).

\section{Kinetics of the disposition of drug-attributable falls in haematocrit}

The kinetics of the deposition of the deficits in haematocrit from 30\% using the lowest recorded haematocrit in the first week of initiating treatment (DAFH) were evaluated as previously described for the general evaluation of kinetics of the disposition of anaemia in malarious children [23, 24]. Briefly, in all children, haematocrit values below pre-treatment levels following initiation of treatment and at follow-up were subtracted from pretreatment haematocrit at each time of measurement until haematocrit rose to or above pre-treatment level and the resulting values plotted against time. The final haematocrit when pre-treatment level was reached was therefore zero in all patients with falls in haematocrit 
following initiation of treatment. However, the final haematocrit at the time when pre-treatment haematocrit level was reached was assumed to be $0.01 \%$ [24]. The areas under the curve (AUC) of deficit in haematocrit from pre-treatment level versus time were obtained by trapezoidal rule using the computer program Turbo Ken (designed by Clinical Pharmacology Group, University of Southampton, United Kingdom) as previously described $[23,24]$. AUC was also obtained manually by calculating the average haematocrit values between two consecutive time measurements and multiplying it by the time interval between the measurements, and summing up all the values, in a manner similar to that for the numerical estimation of area under a drug concentration-time curve (AUC) [25]. The unit of quantification would be \%.d, if haematocrit values were used or g/L.d if haemoglobin values were used. Haematocrit values may be converted to haemoglobin values by dividing by 3 [26]. Semilogarithm plots of deficit in haematocrit from pre-treatment level versus time were plotted. The apparent terminal elimination rate constant $(\lambda)$ was obtained by leastsquare regression analysis of the post-peak log-linear part of the plot of deficit in haematocrit from pretreatment level versus time. The apparent terminal halftime of DAFH $\left(t_{1 / 2(\mathrm{DAFH})}\right)$ was calculated from $\ln 2 / \lambda$ (that is, $\lambda t=0.693$ ). Only children in whom haematocrit values were measured at least 3 times following a drugattributable fall in haematocrit post-initiation of treatment were included in this evaluation.

\section{Statistical analysis}

Data were analyzed using version 6 of Epi-Info software [27] and the statistical program SPSS for Windows version 20.0 [28]. Variables considered in the analysis were related to the densities of $P$. falciparum asexual forms, haematocrit status at presentation and the values of $\mathrm{DAFH}$ and $\mathrm{AUC}_{(\mathrm{DAFH})}$. Proportions were compared by calculating $X^{2}$ using Yates' correction, Fisher's exact or Mantel Haenszel tests. Normally distributed, continuous data were compared by Student's t test and analysis of variance (ANOVA). Kaplan-Meier estimator and pairwise log-rank tests were used to determine cumulative risk of anaemia occurring within 1 week post-treatment initiation with AL, AA or DHP. Stepwise multiple logistic regression models were used to test the association between: anaemia pre-treatment, normal haematocrit pre-treatment progressing to EAA within 1 week posttreatment initiation, malaria-attributable fall in haematocrit (MAFH) in excess of $4 \%$, or drug-attributable fall in haematocrit (DAFH) in excess of $4 \%$, and factors that were significant at univariate analysis. Correlation between the values of DAFH and $\mathrm{AUC}_{(\mathrm{DAFH})}$ in the same patients was assessed by Pearson's correlation coefficient. Agreement between the values of $\mathrm{DAFH}$ and $\mathrm{AUC}_{(\mathrm{DAFH})}$ was assessed by Bland-Altman analysis [29]. Data were double entered serially using patients' codes and were only analyzed at the end of the study.

\section{Results \\ Characteristics of children enrolled in the study and parasite positivity following treatment}

Nine hundred and ninety two children were enrolled and randomized to AL $(n=324)$, AA $(n=321)$ or DHP $(n=347)$ treatments. Of these children, haematocrit values were measured at presentation in 959 children $(n=315,307$ and 337 in AL, AA and DHP treatments, respectively). Mean weight of 959 children enrolled in the study was $13.2 \mathrm{~kg}$ (95\% CI 12.9-13.4). The other characteristics of these children at presentation are shown in Table 1. Two hundred and fifty six of the 959 children $(27 \%)$ were aged $\leq 24$ months and $121(13 \%)$ were aged $\leq 15$ months. One hundred and one (11\%) had asexual parasitaemia $>100,000 \mu \mathrm{L}$ ${ }^{-1}$. Overall, mean haematocrit at presentation was 30.6\% (95\% CI 30.3-30.9). At presentation, anaemia was present in 355 of 959 children (37\%) and it was mild, moderate or severe in 323 (33.7\%), 30 (3.1\%) or 2 children $(0.2 \%)$, respectively (Table 1$)$. Overall, asexual parasite positivity on day 3 was 29 of 959 children $(3 \%)$ and it was similar in all treatments groups [11 of 315 children (3\%), 12 of 307 children (4\%), and 6 of 337 children (2\%) in AL-, AA- and DHPtreated children, respectively, $P=0.24]$.

\section{Factors contributing to anaemia at presentation}

Factors associated with anaemia at presentation are presented in Table 2. In a univariate analysis, an age $\leq$ 15 months, duration of illness $>2$ days, and enrolment asexual parasitaemia $\leq 10,000 \mu \mathrm{L}^{-1}$ were associated with anaemia at presentation. In a multivariate analysis, duration of illness $>2$ days and an enrolment asexual parasitaemia $\leq 10,000 \mu \mathrm{L}^{-1}$ were independent predictors of anaemia at presentation (Table 2).

\section{Recovery from pre-treatment anaemia}

Data for the evaluation of recovery from pre-treatment anaemia were available in 318 of 355 children. Of these children, 142, 101, 58, 26, 8 and 3 children recovered from their anaemia within 1, 2, 3, 4, 5 and 6 weeks posttreatment initiation, respectively. Overall, mean anaemia recovery time was 11.5 days ( $95 \%$ CI $10.5-12.5, n=308$ ). Mean anaemia recovery time was significantly longer in DHP-treated children compared with AL- and AAtreated children $[13.3$ days $(95 \%$ CI $11.5-15.2, n=95)$ versus 11.7 days (95\% CI 9.9-13.6, $n=108)$ versus 9.5 days $(95 \%$ CI $8-11, n=105)$ respectively, $P=0.01$ ]. Ten children did not recover from their pre-treatment anaemia during the entire follow-up period. 
Table 1 Characteristics of the 959 children enrolled in the study of risk factors for anaemia in uncomplicated falciparum malaria

\begin{tabular}{|c|c|c|c|c|c|c|}
\hline \multirow[t]{2}{*}{ Variables } & \multirow{2}{*}{$\begin{array}{l}\text { No. with enrolment } \\
\text { haematocrit, n (\%) }\end{array}$} & \multirow{2}{*}{$\begin{array}{l}\text { Enrolment } \\
\text { haematocrit, } \\
\text { mean }[95 \% \mathrm{Cl}]\end{array}$} & \multicolumn{4}{|c|}{ Anaemia (haematocrit $<30 \%$ ) at presentation, $\mathrm{n}(\%)^{\mathrm{a}}$} \\
\hline & & & $\mathrm{ALL}$ & Mild & Moderate & Severe \\
\hline Total & $959(96.7)$ & $30.6[30.3-30.9]$ & $355(37)$ & $323(33.7)$ & $30(3.1)$ & $2(0.2)$ \\
\hline Male & $522(52.6)$ & $30.5[30.1-31]$ & $197(20.5)$ & $182(19)$ & $14(1.5)$ & $1(0.1)$ \\
\hline Female & $437(44.1)$ & $30.7[30.2-31.2]$ & $158(16.5)$ & $141(14.7)$ & $16(1.6)$ & $1(0.1)$ \\
\hline Aged $^{\mathrm{b}} \leq 15$ months & $121(12.6)$ & $29[28.1-30]$ & $56(5.8)$ & $48(5)$ & $8(0.8)$ & $0(0)$ \\
\hline$\leq 24$ months & $256(25.8)$ & $29.7[29.1-30.3]$ & $108(11.3)$ & $93(9.7)$ & $14(1.5)$ & $1(0.1)$ \\
\hline$>24$ months & $695(70.1)$ & $30.9[30.6-31.2]$ & $244(25.4)$ & $228(23.8)$ & $15(1.6)$ & $1(0.1)$ \\
\hline \multicolumn{7}{|l|}{ Asexual parasitaemiac } \\
\hline$\leq 25,000 \mu \mathrm{L}^{-1}$ & $559(52.3)$ & $30.6[29.6-30.4]$ & $225(23.5)$ & $203(21.2)$ & $20(2.1)$ & $2(0.2)$ \\
\hline$>25,000-50,000 \mu \mathrm{L}^{-1}$ & $141(14.7)$ & $31.2[30.3-32.2]$ & $41(4.3)$ & $35(3.6)$ & $6(0.6)$ & $0(0)$ \\
\hline$>50,000-100,000 \mu \mathrm{L}^{-1}$ & $152(15.8)$ & $31.3[30.4-32.1]$ & $52(5.4)$ & $50(5.2)$ & $2(0.2)$ & $0(0)$ \\
\hline$>100,000 \mu \mathrm{L}^{-1}$ & $101(10.5)$ & $31.4[30.4-32.4]$ & $35(3.6)$ & $33(3.4)$ & $2(0.2)$ & $0(0)$ \\
\hline \multicolumn{7}{|l|}{ Gametocytaemia } \\
\hline Present & $47(4.7)$ & $28.8[27.6-30]$ & $22(2.3)$ & $20(2.1)$ & $2(0.2)$ & $0(0)$ \\
\hline Absent & $912(91.9)$ & 30.7 [30.3-31] & $333(34.7)$ & $303(31.6)$ & $28(2.9)$ & $2(0.2)$ \\
\hline \multicolumn{7}{|l|}{ Region of enrolment } \\
\hline Eastern flank ${ }^{d}$ & $503(50.7)$ & $30.6[30.1-31.1]$ & $175(18.2)$ & $152(15.8)$ & $21(2.2)$ & $2(0.2)$ \\
\hline Western flank ${ }^{\mathrm{e}}$ & $456(46)$ & $30.6[30.1-31]$ & $180(18.8)$ & $171(17.8)$ & $9(0.9)$ & $0(0)$ \\
\hline
\end{tabular}

avalues in parenthesis are expressed as percentage of 992 children randomized

${ }^{b}$ data for age not available in eight children

'data for asexual parasitaemia not available in 6 children

'Eastern flank includes: Numan, Nena, Ogbia and Ogwa in Adamawa, Anambra, Bayelsa and Imo States, respectively

eWestern flank includes: Kura, llorin, Ibadan and Bodinga in Kano, Kwara, Oyo and Sokoto States, respectively

\section{Factors contributing to progression from normal haematocrit} pre-treatment to anaemia within 1 week post -treatment initiation (early-appearing anaemia)

Data for evaluation progression from normal haematocrit pre-treatment to an early-appearing anaemia (EAA) within 1 week post-treatment initiation were available in 604 children. Of these children, 301 children (50\%) progressed to anaemia within 1 week post-treatment initiation. The proportions of non-anaemic children who subsequently progressed to anaemia within 1 week of starting treatment were similar with all three treatments (101 of 191 (53\%) versus 90 of 187 (48\%) versus 110 of 226 children (49\%) in AL, AA and DHP treatments, respectively $P=0.59$ ). The probabilities of progression to anaemia 1 week post-treatment initiation were also similar in all three treatments (Log-rank statistic $=1.24 ; P=0.54$, Fig. 2). Factors contributing to progression to anaemia within 1 week are shown in Table 3 . In a univariate analysis, an age $\leq 15$ months, history of fever at presentation, enrolment haematocrit $\leq 35 \%$ and persistent asexual parasitaemia till 1 or 2 days post-treatment initiation were significantly associated with progression to anaemia within 1 week post-initiation of treatment. In a multivariate analysis, an age $\leq 15$ months, history of fever at presentation and enrolment haematocrit $\leq 35 \%$ were independent predictors of progression to anaemia within 1 week (Table 3).

\section{Recovery from early-appearing anaemia}

Data for evaluation of recovery from EAA were available in 275 of 301 children. Of these children, 166, 71, 19, 9, 3 and 2 children recovered at 1, 2, 3, 4, 5 and 6 weeks post-treatment initiation, respectively. Overall, mean anaemia recovery time was 8.4 days (95\% CI 7.4-9.3, $n=270)$. Anaemia recovery times were similar with all three treatments [8.6 days (95\% CI 6.8-10.4, $n=91$ ) versus 7.3 days (95\% CI 6-8.5, $n=80$ ) versus 9.5 days (95\% CI 8$11, n=99)$ in AL-, AA- and DHP-treated children, respectively $P=0.14]$. Five children did not recover from their anaemia during the entire follow-up period. Anaemia recovery time in children who progressed to EAA was significantly shorter than anaemia recovery time of children who were anaemic at presentation [8.4 days (95\% CI 7.49.3, $n=270$ ) versus 11.5 days (95\% CI $10.5-12.5, n=308)$, respectively $P<0.0001]$.

\section{Time-course of haematocrit following artemisinin-based combination treatments}

Figure 3a shows the time-course of haematocrit in children who were non-anaemic at presentation and those who were anaemic at presentation following ACTs. Following treatment, there was little or no fall in haematocrit in anaemic children compared to non-anaemic children indicating little or no drug-attributable falls in 
Table 2 Predictors of anaemia at presentation in children $<5$ years with uncomplicated falciparum malaria

\begin{tabular}{|c|c|c|c|c|c|c|}
\hline Variable & Total no. & $\begin{array}{l}\text { No. with anaemia } \\
\text { at presentation }\end{array}$ & OR $(95 \% \mathrm{Cl})$ & $P$ value & AOR $(95 \% \mathrm{Cl})$ & $P$ value \\
\hline \multicolumn{7}{|l|}{ Gender } \\
\hline Female & 437 & 158 & 1 & & & \\
\hline Male & 522 & 197 & $1.1(0.8-1.4)$ & 0.66 & - & - \\
\hline \multicolumn{7}{|l|}{ Age (months) } \\
\hline$>15$ & 837 & 296 & 1 & & 1 & \\
\hline$\leq 15$ & 114 & 56 & $1.8(1.2-2.6)$ & 0.01 & $1.5(0.9-2.5)$ & 0.09 \\
\hline \multicolumn{7}{|l|}{ Duration of illness (days) } \\
\hline$\leq 2$ & 295 & 92 & 1 & & 1 & \\
\hline$>2$ & 330 & 138 & $1.6(1.1-2.2)$ & 0.01 & $1.5(1.1-2.1)$ & 0.02 \\
\hline \multicolumn{7}{|c|}{ Enrolment body temperature $\left({ }^{\circ} \mathrm{C}\right)$} \\
\hline$\leq 37.4$ & 357 & 143 & 1 & & & \\
\hline$>37.4$ & 601 & 211 & $0.8(0.6-1.1)$ & 0.14 & - & - \\
\hline \multicolumn{7}{|l|}{ History of fever } \\
\hline Absent & 169 & 70 & 1 & & & \\
\hline Present & 789 & 284 & $1.2(0.9-1.8)$ & 0.22 & - & - \\
\hline \multicolumn{7}{|l|}{ Asexual parasitaemia $\left(\mu \mathrm{L}^{-1}\right)$} \\
\hline$>10,000$ & 389 & 160 & 1 & & 1 & \\
\hline$\leq 10,000$ & 564 & 193 & $1.3(1.1-1.8)$ & 0.003 & $1.5(1.1-2.2)$ & 0.02 \\
\hline \multicolumn{7}{|c|}{ Gametocyte carriage at presentation } \\
\hline Absent & 912 & 333 & 1 & & & \\
\hline Present & 47 & 22 & $1.5(0.6-2.8)$ & 0.2 & - & - \\
\hline \multicolumn{7}{|l|}{ Season of enrolment } \\
\hline Dry (November-March) & 69 & 24 & 1 & & & \\
\hline Wet (April-October) & 890 & 331 & $1.1(0.7-1.9)$ & 0.79 & - & - \\
\hline \multicolumn{7}{|l|}{ Region of enrolment } \\
\hline Eastern flank ${ }^{a}$ & 456 & 180 & 1 & & & \\
\hline Western flank ${ }^{\mathrm{b}}$ & 503 & 175 & $0.8(0.6-1.1)$ & 0.15 & - & - \\
\hline
\end{tabular}

$O R$ odd ratio, $A O R$ adjusted odd ratio, $\mathrm{Cl}$ confidence interval

${ }^{a}$ Eastern flank includes: Numan, Neni, Ogbia and Ogwa in Adamawa, Anambra, Bayelsa and Imo States, respectively

${ }^{b}$ Western flank includes: Kura, Ilorin, Ibadan and Bodinga in Kano, Kwara, Oyo and Sokoto States, respectively

the former. Additionally, the rate of rise in haematocrit was rather 'steep' in anaemic children following treatment. Following initiation of treatment, overall, mean time to nadir hematocrit was reached 2.2 days (95\% CI $2.1-2.4, n=719)$ after initiation of treatment and it was significantly shorter in anaemic compared to nonanaemic children at presentation [1.4 days (95\% CI 1.3$1.7, n=213)$ versus 2.6 days (95\% CI 2.5-2.8, $n=506)$ in anaemic and non-anaemic children, respectively, $P<0.0001]$. Compared with pre-treatment haematocrit, falls in haematocrit to nadir levels were significantly lower in anaemic compared to non-anaemic children $[3.4 \%(95 \%$ CI 3.1-3.8 $n=213)$ versus 5.6\% (95\% CI 5.3-6, $n=506$, respectively, $P<0.0001]$. When falls to nadir haematocrits were expressed as percentages of pre-treatment haematocrit levels, falls were significantly higher in non-anaemic compared to anaemic children [16.3\% (95\% CI 15.5-17.2, $n=506)$ versus $13.1 \%$ (95\% CI $11.9-14.4, n=213$ ), respectively $P<0.0001]$. The time-course of haematocrit were similar with all three treatments (Fig. 3b). Mean time to nadir haematocrit was also similar with all three treatments [2.1 days (95\% CI16.8-2.3, $n=234$ ) versus 2.2 days (95\% CI 2-2.4, $n=234$ ) versus 2.4 days (95\% CI 2.1-2.6, $n=251$ ) in AL-, AA- and DHPtreated children, respectively $P=0.24$ ]. Similarly, when falls to nadir haematocrits were expressed as percentages of pre-treatment haematocrit levels, falls were not significantly different between all three treatments [15.3\% (95\% CI $14.1-16.6, n=234)$ versus $14.8 \%(95 \%$ CI $13.6-16.1, n=234$ ) versus $16 \%$ (95\% CI 14.7-17.2, $n=251)$ in AL-, AA- and DHP-treated children, respectively $P=0.44]$. 


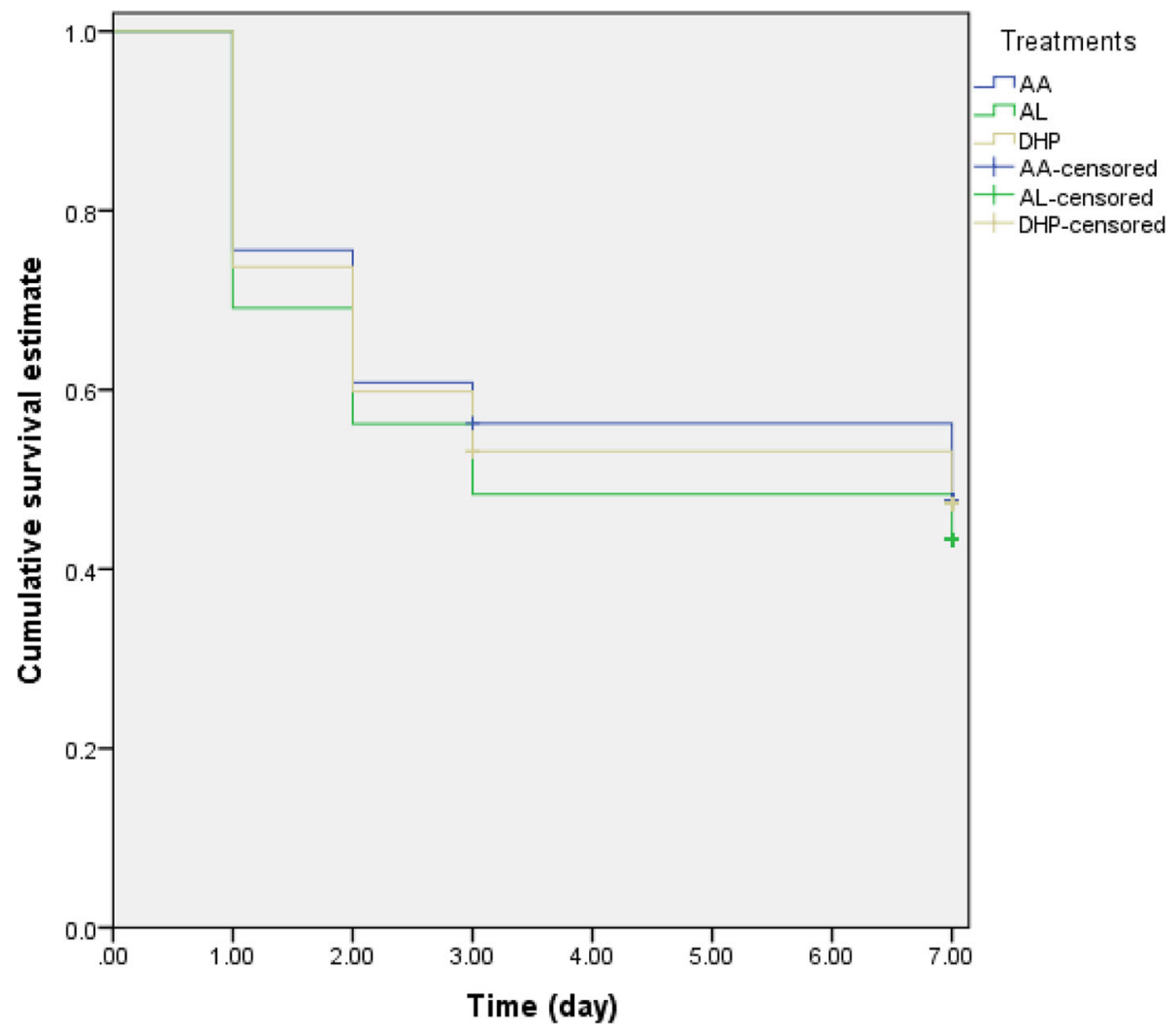

Fig. 2 Kaplan-Meier survival estimates of anaemia occurring within 1 week following treatment with artesunate-amodiaquine (AA, blue line), artemether-lumefantrine (AL, green line) or dihydroartemisinin-piperaquine (DHP, yellow line) in children who were non-anaemic pre-treatment. Log-rank statistic $=1.24, P=0.54$. Pooled data from all sentinel sites. The probabilities of progression to anaemia within 1 week post-treatment were similar with all three treatments

\section{Malaria-attributable fall in haematocrit}

Data for estimation of MAFH were available in 748 children (428 and 320 non-anemic and anaemic children, respectively). In these children, there was no malariaattributable fall in haematocrit following infection in 54 children (49 and 5 non-anaemic and anaemic children, respectively). The proportion of children with no MAFH following treatment was significantly higher in nonanaemic children compared with anaemic children at presentation $(P<0.0001)$. Varying degrees of malariaattributable falls in haematocrit were seen in 694 children (379 and 315 in non-anaemic and anaemic children, respectively). Overall, mean MAFH was 6.8\% (95\% CI $6.5-7.2, n=694$ ) and it was significantly lower in non-anemic compared to anaemic children [4.6\% (95\% CI $4.3-4.9, n=379$ ) versus $9.5 \%$ (95\% CI $9-10, n=315)$, respectively $P<0.0001)$ ].

MAFH in excess of $4 \%$ occurred in 446 of 694 children (64.3\%). The proportion of non-anaemic children with MAFH in excess of $4 \%$ was significantly lower compared to anaemic children (170 of 379 children (44.9\%) versus 276 of 315 children (87.6\%), respectively; $P<0.0001)$ indicating a greater burden of a single episode of infection was borne by anaemic compared to non-anaemic children. Mean MAFH in non-anaemic children were similar for all three treatments [4.8\% (95\% CI 4.3-5.3, $n=$ 117 ) versus $4.8 \%$ (95\% CI $4.3-5.3, n=127$ ) versus $4.8 \%$ (95\% CI 4.3-5.3, $n=135)$ in AL, AA and DHP- treated children, respectively, $P=0.33$ ]. Similarly, mean $\mathrm{MAFH}$ in anaemic children were similar for all three treatments [9.4\% (95\% CI 8.6-10.2, $n=112)$ versus 9.8\% (95\% CI $8.9-10.6, n=107)$ versus $9.3 \%$ (95\% CI 8.3-10.3, $n=96)$ in AL, AA and DHP -treated children, respectively, $P=0.75]$. The proportions of children with MAFH in excess of $4 \%$ were also similar for all three treatments in non-anaemic [56 of 117 versus 58 of 127 versus 56 of 135 children in AL. AA and DHP -treated children, respectively, $P=0.58$ ] and anaemic children [98 of 112 versus 97 of 107 versus 81 of 96 children in AL-, AA- and DHPtreated children, respectively, $P=0.4]$.

Factors associated with MAFH in excess of $4 \%$ are shown in Table 4. In a univariate analysis, an age $\leq$ 38 months, anaemia at presentation, enrolment parasitaemia $\leq 50,000 \mu \mathrm{L}^{-1}$, parasitaemia 1 day after start of treatment and gametocytaemia within 1 week were associated with $\mathrm{MAFH}>4 \%$. In a multivariate analysis, 
Table 3 Predictors of progression from normal haematocrit pre-treatment to anaemia within one week post-initiation of artemisinin-based combination treatments in $<5$ year-old children with uncomplicated falciparum malaria

\begin{tabular}{|c|c|c|c|c|c|c|}
\hline Variable & Total no. & $\begin{array}{l}\text { No. with anaemia } \\
1 \text { week post- } \\
\text { initiation of ACTs }\end{array}$ & OR $(95 \% \mathrm{Cl})$ & $P$ value & AOR (95\% Cl) & $P$ value \\
\hline \multicolumn{7}{|l|}{ Gender } \\
\hline Female & 278 & 132 & 1 & & & \\
\hline Male & 325 & 168 & $0.8(0.6-1.2)$ & 0.34 & - & - \\
\hline \multicolumn{7}{|l|}{ Age (month) } \\
\hline$>15$ & 541 & 255 & 1 & & 1 & \\
\hline$\leq 15$ & 58 & 42 & $2.9(1.6-5.4)$ & $<0.0001$ & $2.5(1.4-4.7)$ & 0.003 \\
\hline \multicolumn{7}{|l|}{ Duration of illness (day) } \\
\hline$\leq 2$ & 203 & 101 & 1 & & & \\
\hline$>2$ & 192 & 100 & $1.0(0.7-1.6)$ & 1.0 & - & - \\
\hline \multicolumn{7}{|c|}{ Enrolment body temperature $\left({ }^{\circ} \mathrm{C}\right)$} \\
\hline$\leq 37.4$ & 214 & 104 & 1 & & & \\
\hline$>37.4$ & 390 & 197 & $1.1(1.0-1.9)$ & 0.71 & - & - \\
\hline \multicolumn{7}{|l|}{ History of fever at enrolment } \\
\hline Absent & 99 & 39 & 1 & & 1 & \\
\hline Present & 505 & 262 & $1.7(1.1-2.6)$ & 0.03 & $1.8(1.1-2.9)$ & 0.01 \\
\hline \multicolumn{7}{|l|}{ Fever on day 1} \\
\hline Absent & 501 & 255 & 1 & & & \\
\hline Present & 70 & 38 & $1.1(0.7-1.9)$ & 0.69 & - & - \\
\hline \multicolumn{7}{|l|}{ Haematocrit (\%) } \\
\hline$>35$ & 140 & 42 & 1 & & 1 & \\
\hline$\leq 35$ & 464 & 259 & $2.9(2.0-4.4)$ & $<0.0001$ & $2.9(1.9-4.4)$ & $<0.0001$ \\
\hline \multicolumn{7}{|l|}{ Parasitaemia $\left(\mu \mathrm{L}^{-1}\right)$} \\
\hline$\leq 50,000$ & 434 & 213 & 1 & & & \\
\hline$>50,000$ & 166 & 87 & $1.1(0.8-1.6)$ & 0.52 & - & - \\
\hline \multicolumn{7}{|l|}{ Parasitaemia on day 1} \\
\hline Absent & 244 & 111 & 1 & & & \\
\hline Present & 360 & 190 & $1.3(1.0-1.9)$ & 0.09 & - & - \\
\hline \multicolumn{7}{|l|}{ Parasitaemia day 1 or 2} \\
\hline Absent & 233 & 104 & 1 & & 1 & \\
\hline Present & 371 & 197 & $1.4(1.0-2.0)$ & 0.04 & $1.3(0.9-1.9)$ & 0.11 \\
\hline \multicolumn{7}{|l|}{ Gametocytaemia } \\
\hline Absent & 579 & 289 & 1 & & & \\
\hline Present & 25 & 12 & $0.9(0.4-2.1)$ & 1.0 & - & - \\
\hline \multicolumn{7}{|l|}{ Parasite clearance time (day) } \\
\hline$\leq 2$ & 468 & 234 & 1 & & & \\
\hline$>2$ & 136 & 67 & $1.0(0.7-1.4)$ & 0.96 & - & - \\
\hline \multicolumn{7}{|l|}{ Fever clearance time (day) } \\
\hline$\leq 2$ & 367 & 186 & 1 & & & \\
\hline$>2$ & 13 & 9 & $1.9(0.9-4.3)$ & 0.13 & - & - \\
\hline \multicolumn{7}{|l|}{ Season of enrolment } \\
\hline Dry (November-March) & 45 & 17 & 1 & & & \\
\hline
\end{tabular}


Table 3 Predictors of progression from normal haematocrit pre-treatment to anaemia within one week post-initiation of artemisinin-based combination treatments in $<5$ year-old children with uncomplicated falciparum malaria (Continued)

\begin{tabular}{llllll}
\hline Variable & Total no. & $\begin{array}{l}\text { No. with anaemia } \\
\text { 1 week post- } \\
\text { initiation of ACTs }\end{array}$ & OR (95\% Cl) & P value & AOR (95\% Cl) \\
\hline $\begin{array}{l}\text { Wet (April-October) } \\
\text { Drug treatment }\end{array}$ & 559 & 284 & $1.7(0.9-3.2)$ & 0.13 & - \\
DHP & 226 & 110 & 1 & & - \\
AL & 191 & 101 & $1.2(0.8-1.7)$ & 0.49 & - \\
AA & 187 & 90 & $1.0(0.7-1.4)$ & 1.0 & -
\end{tabular}

$O R$ odd ratio, $A O R$ adjusted odd ratio, $C l$ confidence interval, $D H P$ dihydroartemisinin-piperaquine, $A L$ artemether-lumefantrine, $A A$ artesunate-amodiaquine, $A C T S$ artemisinin-based combination treatments
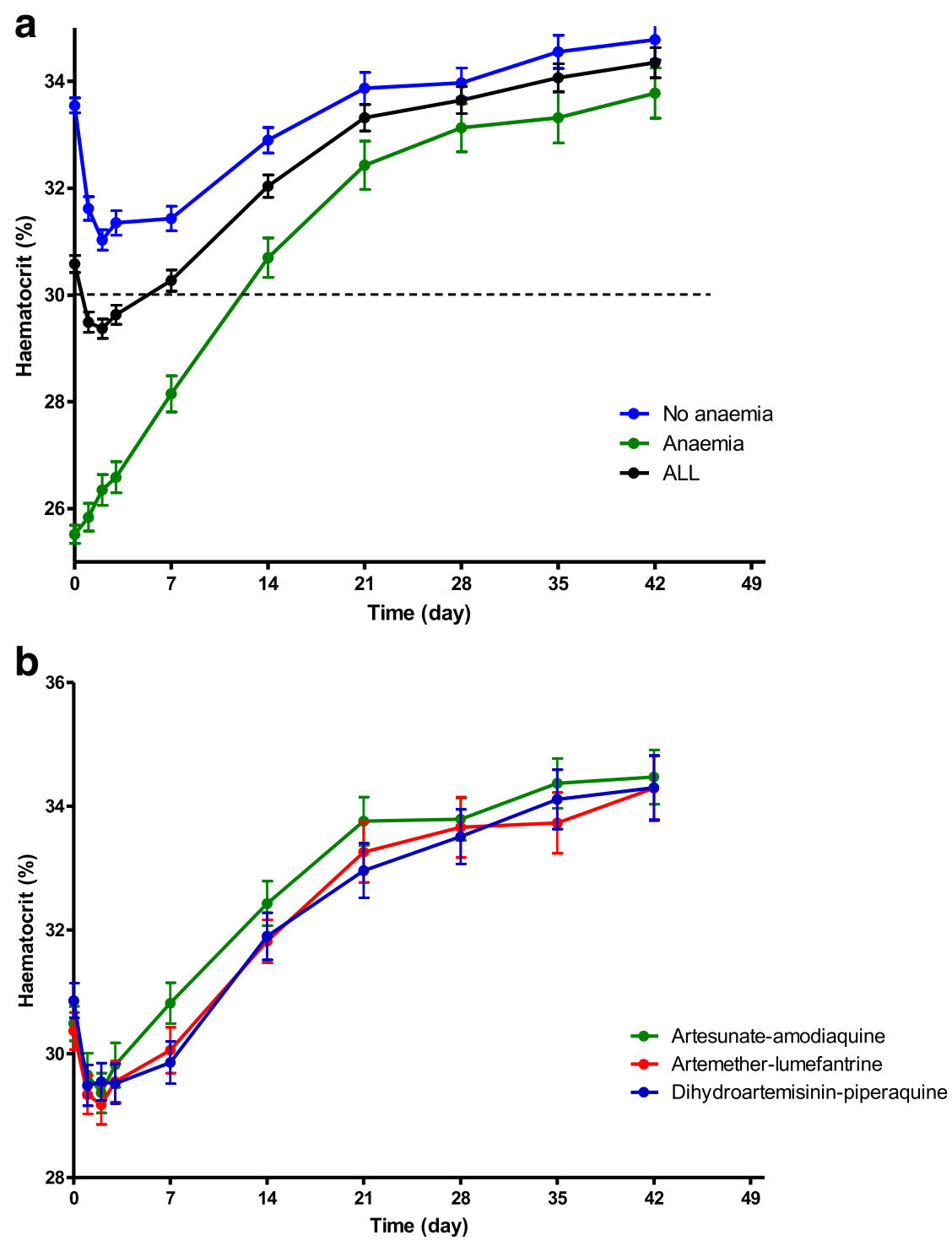

Fig. 3 Time-course of haematocrit in (a) all (black line), anaemic (green line) and non-anaemic (blue line) children following artemisinin-based combination treatments, and (b) in children treated with artemether-lumefantrine (red line), artesunate-amodiaquine (green line) or dihydroartemisininpiperaquine (blue line). Values represent means of haematocrit and standard error of means. Note little or no fall in haematocrit in anaemic children following treatment 
Table 4 Predictors of malaria-attributable fall in haematocrit (MAFH) in excess of $4 \%$ in $<5$ year-old children with uncomplicated falciparum malaria following artemisinin-based combination treatments

\begin{tabular}{|c|c|c|c|c|c|c|}
\hline Variable & Total no. & No. with MAFH >4\% & OR $(95 \% \mathrm{Cl})$ & $P$ value & AOR $(95 \% \mathrm{Cl})$ & $P$ value \\
\hline \multicolumn{7}{|l|}{ Gender } \\
\hline Female & 314 & 203 & 1 & & & \\
\hline Male & 380 & 243 & $1.0(0.7-1.3)$ & 0.91 & - & - \\
\hline \multicolumn{7}{|l|}{ Age (month) } \\
\hline$>38$ & 354 & 213 & 1 & & 1 & \\
\hline$\leq 38$ & 335 & 228 & $1.4(1.0-1.9)$ & 0.04 & $2.1(0.8-1.6)$ & 0.53 \\
\hline \multicolumn{7}{|l|}{ Duration of illness (day) } \\
\hline$\leq 2$ & 200 & 120 & 1 & & & \\
\hline$>2$ & 274 & 180 & $1.1(0.7-1.6)$ & 0.78 & - & - \\
\hline \multicolumn{7}{|c|}{ Enrolment body temperature $\left({ }^{\circ} \mathrm{C}\right)$} \\
\hline$\leq 37.4$ & 264 & 173 & 1 & & & \\
\hline$>37.4$ & 429 & 272 & $0.9(0.7-1.3)$ & 0.63 & - & - \\
\hline \multicolumn{7}{|l|}{ History of fever at enrolment } \\
\hline Absent & 123 & 77 & 1 & & & \\
\hline Present & 571 & 368 & $1.1(0.7-1.6)$ & 0.78 & - & - \\
\hline \multicolumn{7}{|l|}{ Fever on day 1} \\
\hline Absent & 619 & 398 & 1 & & & \\
\hline Present & 62 & 38 & $0.9(0.5-1.5)$ & 0.74 & - & - \\
\hline \multicolumn{7}{|l|}{ Haematocrit (\%) } \\
\hline$\geq 30$ & 379 & 170 & 1 & & 1 & \\
\hline$<30$ & 315 & 276 & $8.7(5.9-12.9)$ & $<0.0001$ & $9.4(6.3-14.1)$ & $<0.0001$ \\
\hline \multicolumn{7}{|l|}{ Parasitaemia $\left(\mu \mathrm{L}^{-1}\right)$} \\
\hline$>50,000$ & 171 & 91 & 1 & & 1 & \\
\hline$\leq 50,000$ & 521 & 355 & $1.9(1.3-2.7)$ & 0.001 & $1.9(1.3-2.9$ & 0.002 \\
\hline \multicolumn{7}{|l|}{ Parasitaemia on day 1} \\
\hline Absent & 380 & 228 & 1 & & 1 & \\
\hline Present & 314 & 218 & $1.5(1.1-2.1)$ & 0.01 & $1.6(1.1-2.3)$ & 0.01 \\
\hline \multicolumn{7}{|l|}{ Gametocytaemia (D0-7) } \\
\hline Absent & 621 & 390 & 1 & & 1 & \\
\hline Present & 73 & 56 & $2.0(1.1-3.4)$ & 0.027 & $2.0(1.0-3.7)$ & 0.04 \\
\hline \multicolumn{7}{|l|}{ Parasite clearance time (days) } \\
\hline$\leq 2$ & 551 & 357 & 1 & & & \\
\hline$>2$ & 142 & 89 & $0.9(0.6-1.3)$ & 0.71 & - & - \\
\hline \multicolumn{7}{|l|}{ Fever clearance time (days) } \\
\hline$\leq 2$ & 416 & 261 & 1 & & & \\
\hline$>2$ & 13 & 11 & $3.3(0.7-14.9)$ & 0.19 & - & - \\
\hline \multicolumn{7}{|l|}{ Season of enrolment } \\
\hline Dry (November-March) & 41 & 23 & 1 & & & \\
\hline Wet (April-October) & 653 & 423 & $1.4(0.8-2.7)$ & 0.34 & - & - \\
\hline \multicolumn{7}{|l|}{ Drug treatment } \\
\hline DHP & 231 & 137 & 1 & & & \\
\hline $\mathrm{AL}$ & 229 & 154 & $1.4(1.0-2.1)$ & 0.1 & - & - \\
\hline AA & 234 & 155 & $1.3(0.9-2.0)$ & 0.15 & & \\
\hline
\end{tabular}

OR odd ratio, $A O R$ adjusted odd ratio, $C l$ confidence interval, $M A F H$ malaria-attributable fall in haematocrit, DHP dihydroartemisinin-piperaquine, $A L$ artemether-lumefantrine, $A A$ artesunate-amodiaquine. D0-7, day $0-7$ 
anaemia at presentation, enrolment parasitaemia $\leq 50,000 \mu \mathrm{L}^{-1}$, parasitaemia 1 day after start of treatments and gametocytaemia within 1 week were independent predictors of MAFH $>4 \%$ (Table 4 ).

\section{Drug-attributable falls in haematocrit}

Data for estimation of DAFH were available in 929 children (588 and 341 non-anaemic and anaemic children at presentation, respectively). In these children, there was no DAFH following treatment in 210 children (82 and 128 non-anaemic and anaemic children, respectively). The proportions of children without DAFH were significantly higher in anaemic compared to non-anaemic children $(P<0.0001$, Fig. 4). Varying degrees of DAFH occurred in 719 children (506 and 213 non-anaemic and anaemic children, respectively; Fig. 4). Overall, lowest falls from pre-treatment levels were seen on day 1, 2 or 3 in 232, 217 or 158 children, respectively. Overall, mean DAFH was $5 \%(95 \%$ CI $4.7-5.2, n=719)$ and it was significantly higher in non-anaemic compared to anaemic children [5.6\% (95\% CI 5.3-5.9, $n=506)$ versus $3.4 \%$ (95\% CI 3.1-3.8, $n=213$ ), $P<0.0001$; Fig. 4) [see also time-course of changes in haematocrit following treatments above]. DAFH in excess of $4 \%$ occurred in 385 of 719 children (53.5\%) [279 of 506 (55.1\%) and 55 of 213 $(25.8 \%)$ in non-anaemic and anaemic children, respectively]. The proportion of non-anaemic children with DAFH in excess of $4 \%$ was significantly higher than in anaemic children $(P<0.0001)$ indicating relative lack of conservation in non-anaemic children and relative conservation in anaemic children.

DAFH in non-anaemic children were similar for all three treatments [5.7\% (95\% CI 5.1-6.2, $n=167)$ versus $5.5 \%(95 \%$ CI $4.9-6.1, n=155)$ versus $5.6 \%$ (95\% CI $5.1-$ $6.2, n=184)$ in AL-, AA- and DHP-treated children, respectively, $P=0.93$ ]. Similarly, mean DAFH in anaemic children were similar for all three treatments $[3.2 \%(95 \%$ CI 2.7-3.7, $n=67$ ) versus $3.2 \%$ (95\% CI 2.7-3.8, $n=79$ ) versus $3.9 \%(95 \%$ CI $3.2-4.5, n=67)$ in AL-, AAand-treated children, respectively, $P=0.2]$. The proportions of children with DAFH in excess of $4 \%$ were also similar for all three treatments in non-anaemic [97 of $167(58 \%)$ versus 82 of 155 (53\%) versus 100 of 184 children (54\%) in AL-, AA- and DHP-treated children, respectively $P=0.62$ ] and in anaemic children [16 of 67 (24\%) versus 19 of 79 (24\%) versus 20 of 67 children (30\%) in AL-, AA- and DHP-treated children, respectively $P=0.66]$.

Factors associated with DAFH in excess of $4 \%$ are shown in Table 5. In a univariate analysis, enrolment body temperature $\geq 38^{\circ} \mathrm{C}$, history of fever at presentation, fever 1 day post-treatment initiation, enrolment haematocrit $\geq 37 \%$, enrolment parasitaemia $>100,000 \mu \mathrm{L}$ -1 , no gametocytaemia at presentation and within one week post-treatment initiation were significantly associated with DAFH $>4 \%$. In a multivariate analysis, history of fever at presentation, fever 1 day posttreatment initiation, enrolment haematocrit $\geq 37 \%$, and
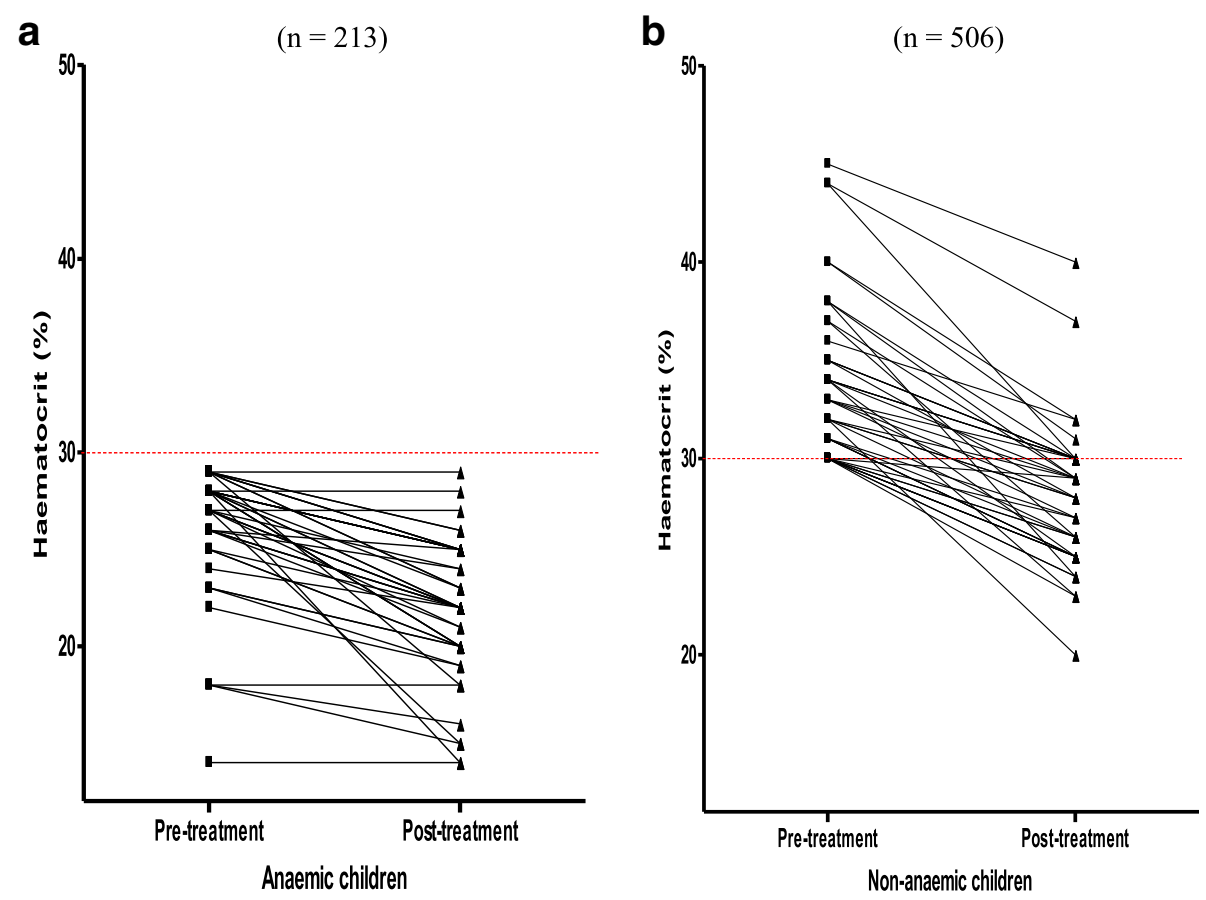

Fig. 4 Drug-attributable falls in haematocrit in anaemic (a) and non-anaemic children (b) following artemisinin-based combination treatments 
Table 5 Predictors of drug-attributable falls in haematocrit (DAFH) in excess of $4 \%$ in $<5$ year-old children with uncomplicated falciparum malaria following artemisinin-based combination treatments

\begin{tabular}{|c|c|c|c|c|c|c|}
\hline Variable & Total no. & No. with DAFH $>4 \%$ & OR $(95 \% \mathrm{Cl})$ & $P$ value & AOR $(95 \% \mathrm{Cl})$ & $P$ value \\
\hline \multicolumn{7}{|l|}{ Gender } \\
\hline Female & 323 & 152 & 1 & & & \\
\hline Male & 395 & 181 & $0.8(0.6-1.1)$ & 0.15 & - & - \\
\hline \multicolumn{7}{|l|}{ Age (month) } \\
\hline$>15$ & 627 & 291 & 1 & & & \\
\hline$\leq 15$ & 88 & 40 & $1.0(0.6-1.5)$ & 0.96 & - & - \\
\hline \multicolumn{7}{|l|}{ Duration of illness (day) } \\
\hline$\leq 2$ & 235 & 125 & 1 & & & \\
\hline$>2$ & 262 & 122 & $0.8(0.5-1.1)$ & 0.17 & - & - \\
\hline \multicolumn{7}{|c|}{ Enrolment body temperature $\left({ }^{\circ} \mathrm{C}\right)$} \\
\hline$<38$ & 389 & 159 & 1 & & 1 & \\
\hline$\geq 38$ & 330 & 175 & $1.6(1.2-2.2)$ & 0.001 & $1.3(1.0-1.8)$ & 0.09 \\
\hline \multicolumn{7}{|l|}{ History of fever at enrolment } \\
\hline Absent & 109 & 26 & 1 & & 1 & \\
\hline Present & 610 & 308 & $3.3(2.0-5.2)$ & $<0.0001$ & $3.0(1.8-4.9)$ & $<0.0001$ \\
\hline \multicolumn{7}{|l|}{ Fever on day 1} \\
\hline Absent & 611 & 267 & 1 & & 1 & \\
\hline Present & 91 & 58 & $2.3(1.4-3.6)$ & 0.001 & $1.8(1.1-2.9)$ & 0.02 \\
\hline \multicolumn{7}{|l|}{ Haematocrit (\%) } \\
\hline$<37$ & 641 & 271 & 1 & & 1 & \\
\hline$\geq 37$ & 78 & 63 & $5.7(3.2-10.3)$ & $<0.0001$ & $5.5(3.0-10.2)$ & $<0.0001$ \\
\hline \multicolumn{7}{|l|}{ Parasitaemia $\left(\mu \mathrm{L}^{-1}\right)$} \\
\hline$\leq 100,000$ & 631 & 227 & 1 & & 1 & \\
\hline$>100,000$ & 85 & 55 & $2.3(1.5-3.8)$ & $<0.0001$ & $2.1(1.3-3.5)$ & 0.004 \\
\hline \multicolumn{7}{|l|}{ Parasitaemia on day 1} \\
\hline Absent & 288 & 133 & 1 & & & \\
\hline Present & 431 & 201 & $1.0(0.8-1.4)$ & 0.84 & - & - \\
\hline \multicolumn{7}{|l|}{ Gametocytaemia (D0) } \\
\hline Present & 31 & 7 & 1 & & 1 & \\
\hline Absent & 688 & 327 & $3.1(1.3-7.3)$ & 0.01 & $1.7(0.5-5.8)$ & 0.36 \\
\hline \multicolumn{7}{|c|}{ Gametocyteamia (within D0-7) } \\
\hline Present & 61 & 16 & 1 & & 1 & \\
\hline Absent & 658 & 318 & $2.6(1.5-4.7)$ & 0.001 & $1.4(0.6-3.3)$ & 0.44 \\
\hline \multicolumn{7}{|l|}{ Parasite clearance time (day) } \\
\hline$\leq 2$ & 563 & 259 & 1 & & & \\
\hline$>2$ & 155 & 75 & $1.1(0.8-1.6)$ & 0.66 & - & - \\
\hline \multicolumn{7}{|l|}{ Fever clearance time (day) } \\
\hline$\leq 2$ & 455 & 223 & 1 & & & \\
\hline$>2$ & 19 & 10 & $1.2(0.5-2.9)$ & 0.94 & - & - \\
\hline \multicolumn{7}{|l|}{ Season of enrolment } \\
\hline Dry (November-March) & 43 & 16 & 1 & & & \\
\hline Wet (April-October) & 676 & 318 & $1.5(0.8-2.8)$ & 0.27 & - & - \\
\hline
\end{tabular}


Table 5 Predictors of drug-attributable falls in haematocrit (DAFH) in excess of $4 \%$ in $<5$ year-old children with uncomplicated falciparum malaria following artemisinin-based combination treatments (Continued)

\begin{tabular}{|c|c|c|c|c|c|c|}
\hline Variable & Total no. & No. with DAFH $>4 \%$ & OR $(95 \% \mathrm{Cl})$ & $P$ value & AOR $(95 \% \mathrm{Cl})$ & $P$ value \\
\hline \multicolumn{7}{|c|}{ Drug treatment } \\
\hline DHP & 251 & 120 & 1 & & & \\
\hline $\mathrm{AL}$ & 234 & 113 & $1.0(0.7-1.5)$ & 0.99 & - & - \\
\hline AA & 234 & 101 & $0.8(0.6-1.2)$ & 0.35 & & \\
\hline
\end{tabular}

$O R$ odd ratio; $A O R$ adjusted odd ratio, $C I$ confidence interval, $D A F H$ drug-attributable fall in haematocrit, $D H P$ dihydroartemisinin-piperaquine, $A L$ artemether-lumefantrine, $A A$ artesunate-amodiaquine

enrolment parasitaemia $>100,000 \mu \mathrm{L}^{-1}$ were independent predictors of DAFH $>4 \%$ (Table 5 ).

Of the non-anaemic children who subsequently became anaemic 1 week after start of treatment [EAA], 245 of 298 children (82\%) had DAFH $>4 \%$. At a DAFH of $4 \%, 84$ of 301 non-anaemic children at presentation (28\%) progressed to anaemia within 1 week. At a DAFH of $10 \%, 121$ of 301 non-anaemic children at presentation (40\%) progressed to anaemia within 1 week.

\section{Kinetics of the disposition of drug-attributable falls in haematocrit}

The demographic and other characteristics of the 432 children enrolled in kinetics of the disposition of DAFH study ( $n=148$ for AL, $n=138$ for AA and $n=146$ for DHP) are shown in Table 6. Overall, there was a monoexponential decline of the deficits in DAFH with an estimated mean half-time ( $\left.t_{1 / 2 \mathrm{el}}\right)$ of 2.2 days (95\% CI 1.9-2.6) (Fig. 5a). Estimated $t_{1 / 2 \mathrm{el}}$ was significantly higher in children treated with DHP compared to AA and AL [2.8 days (95\% CI $2.1-3.5, n=146)$ versus 1.6 days (95\% CI $1.3-2, n=138$ ) versus 2.2 days (95\% CI $1.7-2.8, n=148$ ), respectively $P=0.01$ ] but it was similar between AA and AL $(P=0.27)$. Estimated $t_{1 / 2 e l}$ was also significantly higher in children who were non-anaemic compared to anaemic children at presentation [2.7 days (95\% CI 2.2-3.1, $n=318$ ) versus 1.1 days (95\% CI 0.9-1.2, $n=114) P<0.0001$ ] (Fig. 5b).

Overall, estimated mean estimated $\mathrm{AUC}_{(\mathrm{DAFH})}$ was 56.3\%.day (95\% CI 48.5-64.2). Estimated mean $\mathrm{AUC}_{\mathrm{DAFH}}$ was significantly higher in children treated with DHP compared to AA and AL [67\%.day (95\% CI 57.4-82.6, $n=146$ ) versus $41.7 \%$.day $(95 \% \quad C I \quad 32.5-50.8, n=138)$ versus $59.5 \%$.day (95\% CI 44.7-74.3, $n=148$ ), respectively $P=0.03$ ] but it was similar between AA and AL $(P=0.16)$. Estimated mean $\mathrm{AUC}_{\mathrm{DAFH}}$ was also significantly higher in children who were non-anaemic compared to anaemic children at presentation [66.1\%.day (95\% CI 57-75.2, $n=317$ ) versus 29.3\%.day (95\% CI 14.5-44.1, $n=114) P<0.0001]$.

Relationship between area under curve of the plot of deficit in drug-attributable falls in haematocrit and value of drug-attributable falls in haematocrit

The relationship between $\mathrm{AUC}_{(\mathrm{DAFH})}$ and the value of DAFH was evaluated in 432 children. The mean of the ratio of $\mathrm{AUC}_{(\mathrm{DAFH})}$ : value of DAFH was 8.8 (95\% CI 7.410.3). There was a significantly positive correlation between $\mathrm{AUC}_{(\mathrm{DAFH})}$ and value of DAFH $(r=0.47, P<0.0001)$. Bland-Altman plots of $\mathrm{AUC}_{(\mathrm{DAFH})}$ and multiples of values of DAFH are shown in Fig. 6. The limits of agreement between $\mathrm{AUC}_{(\mathrm{DAFH})}$ and 9 or 10 multiples of value of $\mathrm{DAFH}$ were narrow. At 9 and 10 multiples of value of DAFH, the limits of agreement were $-142.1-148.6 \%$ and $-147.4-$ $142.1 \%$, respectively. The bias at multiples of 9 or 10 value of DAFH was statistically insignificant $(P=0.36$ and 0.46 , respectively) indicating that $\mathrm{AUC}_{(\mathrm{DAFH})}$ and 9 or 10 multiples of value of DAFH can be used interchangeably in the same patient. However, there was a statistically significant bias at 8 multiples of value of DAFH $(P=0.01)$.

\section{Discussion}

In this study, we evaluated prospectively in young malarious children, the factors contributing to: anaemia at presentation, anaemia one week after starting treatment in children who were not anaemic at presentation, the burden of anaemia imposed by a single episode of malaria, the falls and the duration of falls in haematocrit attributable to three ACTs. Our results showed: anaemia is common at presentation and in the one week following initiation of treatment; the burden of anaemia after a single episode of infection is high; and drug related falls in haematocrit are significantly more common and more severe in children who were not anaemic at presentation compared with those who were anaemic at presentation.

Compared with factors contributing to anaemia during the early period of adoption of ACTs as first-line antimalarials in the study areas [8], the factors contributing to anaemia ten years after adoption as first-line treatments appeared to have been considerably modified as shown in the results of the present study. The significant modifications include: reduction in age band susceptible to malarial anaemia at presentation from children 659 months to children 6-15 months and relatively low gametocyte carriage at presentation or following treatment. However, the prevalence of anaemia at presentation and the burden of anaemia following a single episode of infection appeared to have been little affected. The low gametocyte carriage ten years following adoption as first-line antimalarials can be attributable to rapid 
Table 6 Demographic and clinical characteristics of $<5$ years old children with uncomplicated falciparum malaria enrolled in study of the kinetics of the disposition of drug-attributable falls in haematocrit following artemisinin-based combination treatments

\begin{tabular}{|c|c|c|c|c|c|}
\hline & \multicolumn{4}{|l|}{ Treatment } & \multirow[t]{2}{*}{$P$ value } \\
\hline & $\overline{\mathrm{AA}(n=138)}$ & $\mathrm{AL}(n=148)$ & $\operatorname{DHP}(n=146)$ & $\operatorname{ALL}(n=432)$ & \\
\hline Male/Female & $78 / 60$ & $74 / 74$ & $82 / 64$ & $234 / 198$ & 0.45 \\
\hline \multicolumn{6}{|l|}{ Age (month) } \\
\hline Mean $(95 \% \mathrm{Cl})$ & $38.4(35.6-41.2)$ & $41(38.5-43.6)$ & $36.5(33.6-39.2)$ & $38.6(37.1-40.2)$ & 0.06 \\
\hline Age $\leq 24$ [\%] & $36[26]$ & $27[18]$ & $53[36]$ & $116[27]$ & 0.002 \\
\hline \multicolumn{6}{|l|}{ Duration of illness (day) } \\
\hline Mean $(95 \% \mathrm{Cl})$ & $3.6(3.1-4.1)$ & $3.6(3.1-4.1)$ & $3.4(2.9-3.9)$ & $3.5(3.2-3.8)$ & 0.79 \\
\hline \multicolumn{6}{|l|}{ Temperature $\left({ }^{\circ} \mathrm{C}\right)$} \\
\hline Mean $(95 \% \mathrm{Cl})$ & $37.9(37.7-38.1)$ & $37.9(37.5-38.2)$ & $37.8(37.4-38.2)$ & $37.9(37.6-38.1)$ & 0.76 \\
\hline \multicolumn{6}{|l|}{ No. with temperature } \\
\hline$>37.4^{\circ} \mathrm{C}[\%]$ & $94[68]$ & $104[70]$ & $95[65]$ & $293[68]$ & 0.63 \\
\hline$>40{ }^{\circ} \mathrm{C}[\%]$ & $9[6.5]$ & $4[3]$ & $7[5]$ & $20[5]$ & 0.29 \\
\hline \multicolumn{6}{|l|}{ Haematocrit (\%) } \\
\hline Mean $(95 \% \mathrm{Cl})$ & $31.8(31-32.6)$ & $31.9(31.2-32.7)$ & $32.3(31.5-33)$ & $32(31.6-33.4)$ & 0.67 \\
\hline No. with haematocrit <30\% [\%] & $44[32]$ & $40[27]$ & $34[23]$ & $114[26]$ & 0.54 \\
\hline \multicolumn{6}{|l|}{ Parasitaemia $\left(\mu \mathrm{L}^{-1}\right)$} \\
\hline Geometric mean & 17,737 & 22,202 & 20,767 & 20,210 & 0.36 \\
\hline Range & $2000-200,000$ & $2004-200,000$ & $2003-200,000$ & $2000-200,000$ & \\
\hline \multicolumn{6}{|l|}{ No with parasitaemia } \\
\hline$>100,000[\%]$ & 90 [65] & $102[69]$ & 99 [68] & $291[67]$ & 0.84 \\
\hline Gametocyte carriage [\%] & $12[8.7]$ & $7[4.7]$ & $11[7.5]$ & $30[6.9]$ & 0.38 \\
\hline \multicolumn{6}{|l|}{ Fever clearance time (day) } \\
\hline Mean $(95 \% \mathrm{Cl})$ & $1.1(1.1-1.2)$ & $1.3(1.2-1.4)$ & $1.2(1.1-1.3)$ & $1.2(1.2-1.3)$ & 0.07 \\
\hline \multicolumn{6}{|l|}{ Parasite positivity } \\
\hline On day 1 [\%] & $75[54]$ & $98[66]$ & $81[55]$ & $254[59]$ & 0.07 \\
\hline On day 3 [\%] & $2[1.4]$ & $3[2]$ & $2[1.4]$ & $9[2.1]$ & 0.66 \\
\hline \multicolumn{6}{|l|}{ Parasite clearance time (day) } \\
\hline Mean $(95 \% \mathrm{Cl})$ & $1.8(1.6-1.9)$ & $1.9(1.8-2)$ & $1.7(1.6-1.8)$ & $1.8(1.7-1.9)$ & 0.054 \\
\hline
\end{tabular}

$A A$ artesunate-amodiaquine, $A L$ artemether-lumefantrine, $D H P$ dihydroartemisinin-piperaquine, $C l$ confidence interval

clearance of asexual parasitaemia [17, 23, 30, 31] and alteration in gametocyte sex ratios [32, 33] which can produce a female bias sex ratio that is less infective to mosquitoes [34]. It has also been postulated that ACTs can mobilize immature gametocytes from bone marrow to peripheral blood where they can be rapidly eliminated by components of ACTs $[30,33]$. The latter can also prevent development of immature gametocytes which are non-infective to mosquitoes to mature gametocyte which are infective to mosquitoes [30,33]. This is particularly important because all components of ACTs can kill immature gametocytes. It is not apparent from the results of the present study why a low asexual parasitaemia is a predictor of anaemia at presentation. This finding is paradoxical.
Progression to anaemia within one week of treatment initiation in a half of the children who were not anaemic at presentation can be clearly attributable to relatively high DAFH values with all three treatments. These children differ significantly from anaemic children at presentation in whom DAFH values were relatively low and who did not have a worsening of their anaemia in the one week following treatment initiation (Fig. 5). This finding in anaemic children suggests considerable degree of "haematocrit conservation" [31, 35]. Taking together, this would suggest the three ACTs may prevent further falls in haematocrit in anaemic children at presentation and in half of non-anaemic children at presentation.

The burden of anaemia imposed by a single episode of infection was relatively high and it occurred in two-third of the young malarious children. In these children, 

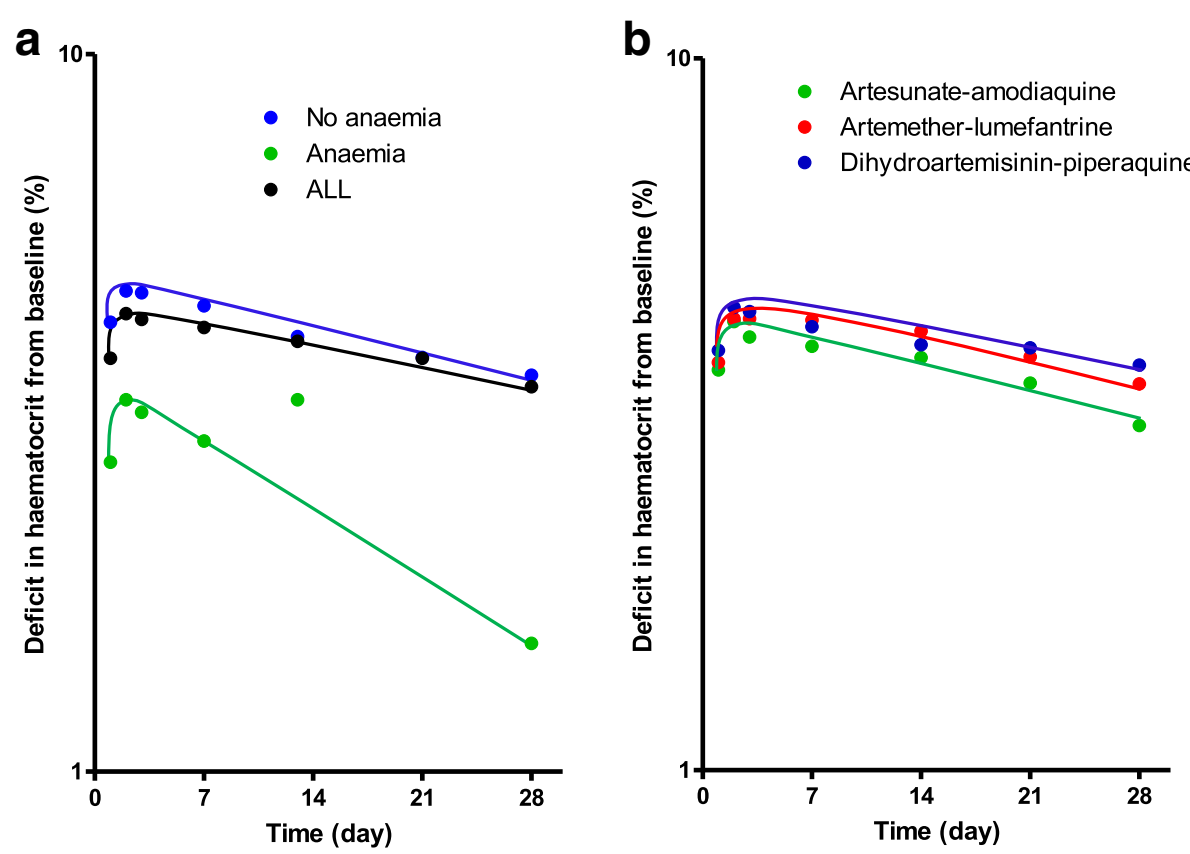

Fig. 5 Semilog plots of deficit in haematocrit from baseline versus time (a) in all children (black line), anaemic (green line) and non-anaemic children (blue line) and (b) in children treated with artemether lumefantrine (red line), artesunate-amodiaquine (green line) or dihydroartemisinin-piperaquine (blue line)

repeated attacks of acute infections within a short time frame can be expected to lead to development of anaemia [16]. Expectedly, anaemia and gametocytaemia at presentation predicted $\mathrm{MAFH}>4 \%$. Indeed the risk of $\mathrm{MAFH}>4 \%$ was approximately nine and a half fold higher in anaemic compared to non-anaemic children at presentation (Table 4). Taking together with factors predicting anaemia at presentation, it would appear that by reducing the age band susceptible to malaria at presentation from 6 to 59 months to $6-15$ months, ACTs have, during the ten years of adoption as first-line treatments, not reduced the burden of anaemia imposed by a single episode of an apparently uncomplicated infection. We have no ready explanation for a presenting parasitaemia $\leq 50,000 \mu \mathrm{L}^{-1}$ being a predictor of MAFH in excess of $4 \%$.

The early-appearing anaemia in $50 \%$ of non-anaemic children was clearly attributable to DAFH in excess of $4 \%$ (see above, paragraph 3). Therefore, all of the predictors of DAFH in excess of $4 \%$ were not unexpected (Table 5). However, there is no ready explanation from the results presented for temperature in excess of $37.9^{\circ} \mathrm{C}$ being a predictor of DAFH in excess of $4 \%$. In this context, there is need to justify the use of DAFH $>4 \%$ as cut off for predictors of DAFH. Firstly, this cut off has been used in a previous study [16]. Second, a $\geq 5 \%$ (5 units) fall in haematocrit from baseline is unlikely to be a random effect and likely to represent a significant fall from baseline in a manner similar to using $95 \%$ confidence interval in a two-way analysis of variance [30].
An important question arising from the present study is whether there are differences in the recovery from anaemia attributable to infections (pre-treatment anaemia) and the anaemia which follows treatment of the infections in patients who were not previously anaemic at presentation (early-appearing anaemia). Overall, it would appear there are significant differences as evidenced by the significantly longer anaemia recovery time in children with anaemia primarily due to the infections compared to the anaemia following treatment of the infections. Additionally, pre-treatment anaemia is primarily due to interaction(s) between host and the parasites while the anaemia following treatment is due to interaction(s) between host, parasite and the drug. A striking feature of all non-anaemic children pretreatment who progressed to early-appearing anaemia were: most had pre-treatment haematocrit close to the lower threshold of normal and the critical falls in haematocrit at which all progressed to anemia was a drugattributable fall in excess of $10 \%$ (Fig. 4). Perhaps determining threshold for progression of all those developing early appearing anaemia should form routine part of the clinical evaluation of drug-attributable falls in haematocrit following different drug regimens. The pre-treatment haematocrit threshold in the cohort of children with normal haematocrit at presentation appears to be a haematocrit of $40 \%$.

The ratio of the estimated $\mathrm{AUC}_{(\mathrm{DAFH})}$ to value of $\mathrm{DAFH}$ was approximately nine folds. This ratio represents the 


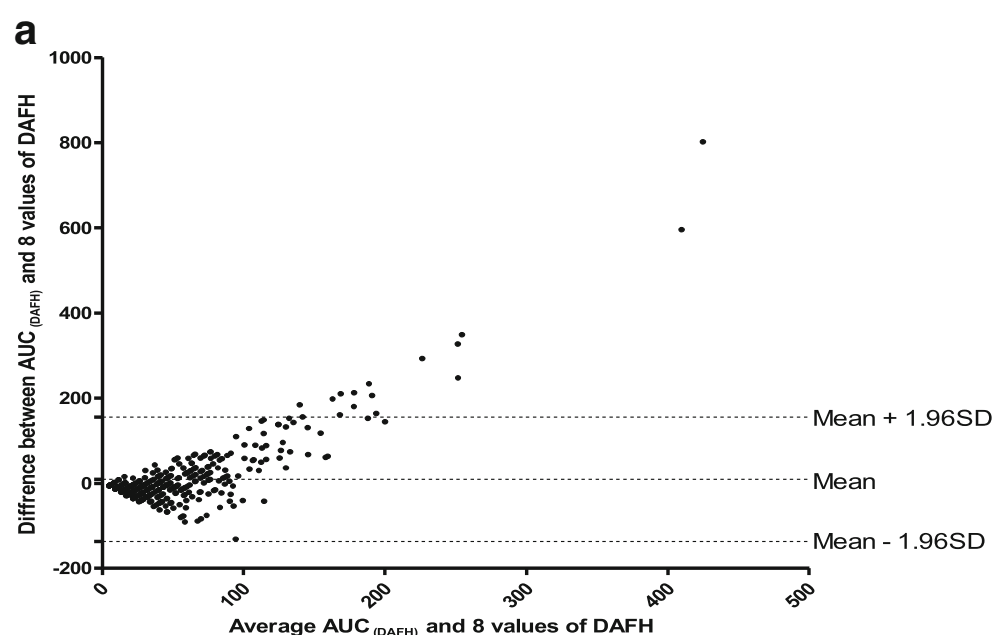

b

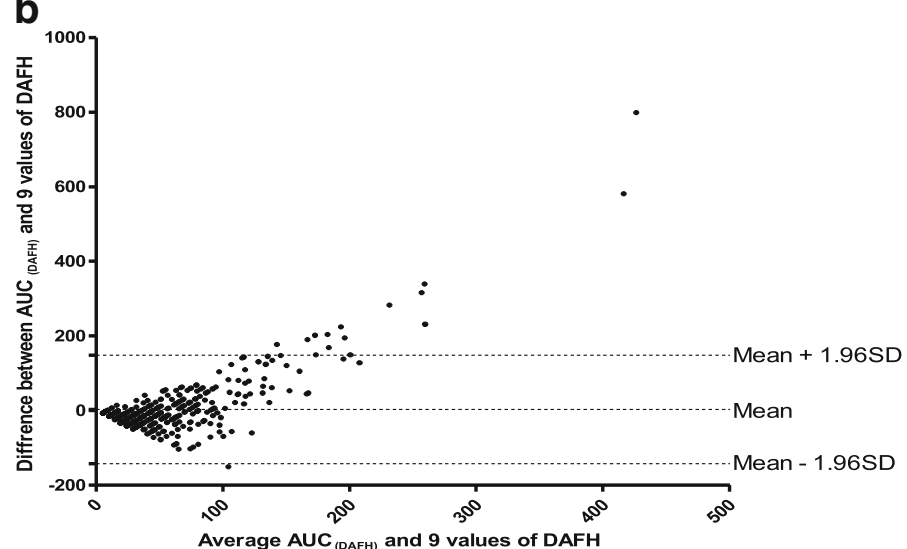

C

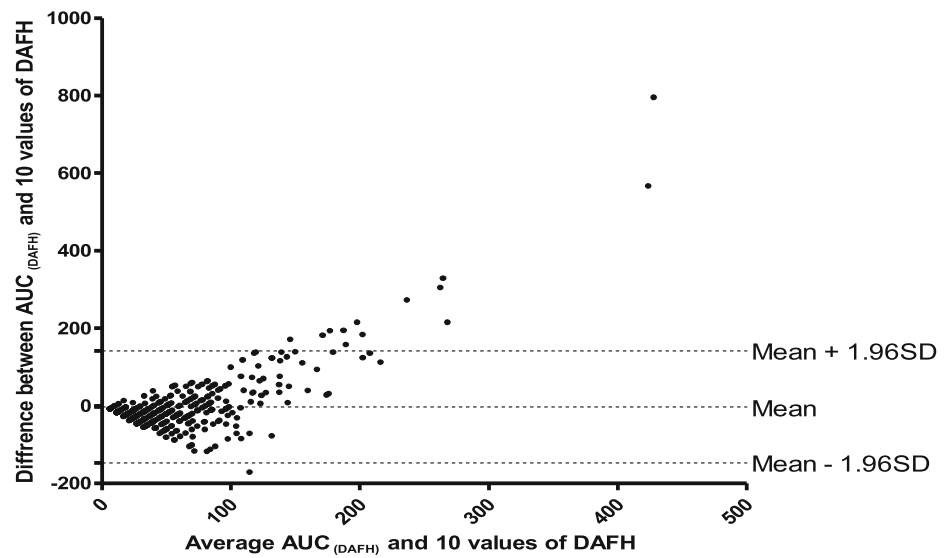

Fig. 6 Bland-Altman plots of area under curve of drug-attributable fall in haematocrit (AUC(DAFH) and multiples [8 (a), 9 (b) and 10 (c)] of values of drug-attributable falls in haematocrit. Biases were $9.18,3.27$ and -2.63 for plots $A, B$ and $C_{;} P=0.01,0.36$ and 0.46 , respectively. The mean values \pm 1.96 standard deviation (SD) of the differences are shown

relationship of a pharmacokinetic estimate to a pharmacodynamic estimate - two methods of measuring DAFH in the same patients employed in the present study. An intriguing feature of the ratio is: it is somewhat similar to the number of half-times required for $>99.9 \%$ completion of a pharmacokinetic process in a rudimentary one-compartment pharmacokinetic model. A somewhat more intriguing finding is their insignificant agreement when 9 or 10 multiples of value of DAFH and $\mathrm{AUC}_{(\mathrm{DAFH})}$ were subjected to Bland-Altman analyses. 
The analyses indicate both measurements can be used interchangeably in the same patients despite the difference in their units of measurement. The difference in units of measurement would suggest some further application of Bland-Altman analysis when applied to establishing agreement between pharmacokinetic and pharmacodynamic processes in clinical drug studies.

The main limitation of the present study is not quantifying once-infected red blood cells. Quantification of once-infected red blood cells would have enabled the study to distinguish between non-anaemic children at presentation who progressed to early-appearing anaemia from those who did not. Another limitation is that the study did not evaluate the contribution of the background causes of anaemia, to the factors contributing to anaemia pre- and post-treatment initiation.

\section{Conclusions}

In conclusion, after ten years of adopting of ACTs as first-line antimalarials in Nigeria, anaemia is common pre-and early post-treatment, anaemia burden of a single infection is relatively high, and drug-attributable falls in haematocrit $>4 \%$ is common and significantly lower in anaemic compared to non-anaemic malarious children.

\begin{abstract}
Abbreviations
$\%$ : Percent; ${ }^{\circ} \mathrm{C}$ : Degree celsius; AA: Artesunate-amodiaquine; ACTs: Artemisinin-based combination treatments; AL: Artemether-lumefantrine; AOR: Adjusted odds ratio; AUC: Area under curve; $A \cup C_{(\mathrm{DAFH})}$ : Area under curve of drug-attributable falls in haematocrit versus time; Cl: Confidence interval; d: Day; DAFH: Drugattributable falls in haematocrit; DHP: Dihydroartemisinin-piperaquine EAA: Early-appearing anaemia; g: Gram; kg: Kilogram; L: Litre; M/F: Male/ female; MAFH: Malaria-attributable fall in haematocrit; mg: Milligram; OR: Odds ratio; $\mathrm{t}_{1 / 2}$ : Half-time; TMAFH: Total malaria-attributable fall in haematocrit; $\mu \mathrm{L}$ : Microliter
\end{abstract}

\section{Acknowledgements}

We are grateful to the parents/guardians and the children who participated in the study.

\section{Funding}

The therapeutic efficacy study from which the data were derived received financial support from Global Fund for AIDS, Tuberculosis and Malaria, United States Presidential Malaria Initiative (PMI), and Malaria Consortium Grants to The Federal Ministry of Health, Abuja, through Drug Therapeutic Efficacy Testing in Nigeria. Logistic support was provided by The Government of the States where the sites are located.

\section{Availability of data and materials}

The dataset supporting the findings of this article are available from the corresponding author upon request.

\section{Authors' contributions}

AS led the design, conduct, data analysis and manuscript preparation. BF was involved in data analysis; KA in data collection, analysis and manuscript preparation; OAW in data analysis, CA in data management; FF, JE, NJ, JA, RW, GN, OM, GE, NE, WAO, FU in data collection; AIA, EOA, GOG, OAF, CTH, SO in data analysis. CA, FF, JE, NJ, JA, RW, GN, OM, GE, WAO and FU made substantial contributions to the conception, design and conduct of the study. AS, FF, JE, NJ, JA, RW, OM and GE were Principal Investigators at the sentinel sites. All authors read, contributed and approved the final draft of the manuscript.

\section{Ethics approval and consent to participate}

The study protocol was approved by National Health Research Ethics Committee, Abuja, Nigeria. NHREC/01/01/2007-28/10/2013 (29 October 2013), NHREC/01/01/ 2007-22/10/2014 (30 October 2014). Written informed consents were obtained from parents/guardians of the children.

\section{Consent for publication}

Not applicable

\section{Competing interests}

The authors declare they have no competing interests.

\section{Publisher's Note}

Springer Nature remains neutral with regard to jurisdictional claims in published maps and institutional affiliations.

\section{Author details}

${ }^{1}$ Antimalarial Therapeutic Efficacy Monitoring Group, National Malaria Elimination Programme, The Federal Ministry of Health, Abuja, Nigeria. ${ }^{2}$ Department of Pharmacology and Therapeutics, University of Ibadan, Ibadan, Nigeria. ${ }^{3}$ Institute for Medical Research and Training, University of Ibadan, Ibadan, Nigeria. “World Health Organization, Country Office, Kampala, Uganda. ${ }^{5}$ Department of Medical Laboratory Science, University of Lagos, Lagos, Nigeria. ${ }^{6}$ Department of Paediatrics, Federal Medical Centre, Yenagoa, Nigeria. ${ }^{7}$ Department of Paediatrics, Nnamdi Azikiwe University, Awka, Nigeria. ${ }^{8}$ Department of Paediatrics, Uthman Dan Fodio University, Sokoto, Nigeria. ${ }^{9}$ Department of Paediatrics, University of Maiduguri, Maiduguri, Nigeria. ${ }^{10}$ Department of Paediatrics, Ahmadu Bello University, Zaria, Nigeria. ${ }^{11}$ Department of Paediatrics, University of Ilorin, Ilorin, Nigeria. ${ }^{12}$ Department of Paediatrics, Imo State University Teaching Hospital, Orlu, Nigeria.

${ }^{13}$ Department of Paediatrics, University of Ibadan, Ibadan, Nigeria.

${ }^{14}$ Department of Physiology, University of Ibadan, Ibadan, Nigeria.

${ }^{15}$ Department of Pharmacology and Toxicology, University of Ibadan, Ibadan, Nigeria. ${ }^{16}$ Department of Biological Sciences and African Centre of Excellence for Genomics of Infectious Diseases (ACEGID), Redeemer University, Ede, Nigeria. ${ }^{17}$ Department of Paediatrics, University of Jos, Jos, Nigeria.

${ }^{18}$ Department of Medical Microbiology and Parasitology, University of Lagos, Lagos, Nigeria. ${ }^{19}$ Department of Medical Laboratory Science, University of Calabar, Calabar, Nigeria. ${ }^{20}$ Department of Clinical Pharmacology, University College Hospital, Ibadan, Nigeria.

Received: 4 July 2017 Accepted: 30 November 2017

Published online: 19 December 2017

\section{References}

1. Bosman A, Mendis KNA. Major transition in malaria treatment: the adoption and deployment of artemisinin-based combination therapies. Am J Trop Med Hyg. 2007;66(Suppl 6):193-7.

2. World Health Organization. World malaria report 2015. Geneva: WHO; 2015. http://www.who.int/malaria/publications/world-malaria-report-2015/report/en/

3. World Health Organization. Antimalarial Drug Combination Therapy. Report of a WHO Technical Consultation. Geneva: World Health Organization. 2001 WHO/CDS/RBM/2001.35.

4. Carrara VI, Zwang J, Ashley EA, Price RN, Stepniewka K, Marion B, Brockman A, Anderson T, McGready R, Phaiphun L, Stephane P, van Vugt M, Hutagalung R, Lwin KM, Phyo AP, Piyanuch P, Imwong M, Pukrittayakamee S, Singhasivanon P, White NJ, Nosten F. Changes in the treatment responses to artesunatemefloquine on the northwestern border of Thailand during 13 years of continuous deployment. PLoS One. 2009;4:e4551.

5. Phyo AP, Ashley EA, Anderson TJC, Bozdech Z, Carrara VI, Sriprawat K, Nair S, White MM, Dziekan J, Ling C, Proux S, Konghahong K, Jeeyapant A, Woodrow CJ, Imwong M, McGready R, Lwin KM, Day NPJ, White NJ, Nosten F. Declining efficacy of artemisinin combination therapy against $P$. falciparum malaria on the Thai-Myanmar border (2003-2013): the role of parasite genetic factors. Clin Infect Dis. 2016;63:784-91.

6. Federal Ministry of Health. National Antimalaria Treatment Guideline. Abuja, Nigeria: Federal Ministry of Health; 2005.

7. Nkuo-Akenji TK, Chi PC, Cho JF, Ndamukong KK, Sumbele I. Malaria and helminth co-infection in children living in a malaria endemic setting of Mount Cameroon and predictors of anemia. J Parasitol. 2006;92:1191-5. 
8. Sowunmi A, Gbotosho GO, Happi CT, Fateye B. Factors contributing to anaemia after uncomplicated Plasmodium falciparum malaria in children Acta Trop. 2010;113:155-61.

9. Sumbele IUN, Samje M, Nkuo-Akenji TA. Longitudinal study on anaemia in children with Plasmodium falciparum infection in the Mount Cameroon region: prevalence, risk factors and perceptions by caregivers. BioMed Central of Infectious Diseases. 2013;13:123.

10. Price RC, Simpson JA, Nosten F, Luxemberger C, Hkirjaroen L, ter Kuile F, Chongsuphajaisiddhi T, White NJ. Factors contributing to anemia after uncomplicated falciparum malaria. Am J Trop Med Hyg. 2001;65:614-22.

11. Dondorp AM, Angus BJ, Chotivanich K, Silamut K, Ruangveerayuth R, Hardeman MR, Kager PA, Vreeken J, White NJ. Red blood cell deformability as a predictor of anemia in severe falciparum malaria. Am J Trop Med Hyg. 1999;60:733-7.

12. Safeukui I, Correas JM, Brousse V, Hirt D, Deplaine G, Mulé S, Lesurtel M, Goasguen N, Sauvanet A, Couvelard A, Kerneis S, Khun H, Vigan-Womas I, Ottone C, Molina TJ, Tréluyer JM, Mercereau-Puijalon O, Milon G, David PH, Buffet PA. Retention of Plasmodium falciparum ring-infected erythrocytes in the slow, open microcirculation of the human spleen. Blood. 2008:112: 2520-8.

13. Buffet PA, Safeukui I, Deplaine G, Brousse V, Prendki V, Thellier M, Turner GD, Mercereau-Puijalon $\mathrm{O}$. The pathogenesis of Plasmodium falciparum malaria in humans: insights from splenic physiology. Blood. 2011;117:381-92.

14. Ouédraogo HZ, Zeba A, Dramaix-Wilmet M, Donnen P. Moderate to severe anaemia due to afebrile Plasmodium falciparum infections in children aged 6- 23 months from rural district of Kongoussi, Burkina Faso. J Trop Pediatr. 2008;54:395-400

15. Njua-Yafi C, Achidi EA, Anchang-Kimbi JK, Apinjoh TO, Mugri RN, Chi HF, Tata RB, Njumkeng C, Nkock EN, Nkuo-Akenji T. Malaria, helminths, coinfection and anaemia in a cohort of children from Mutengene, south western Cameroon. Malar J. 2016;15:69.

16. Sowunmi A, Balogun ST, Gbotosho GO, Happi CT. Effects of amodiaquine, artesunate, and artesunate-amodiaquine on Plasmodium falciparum malariaassociated anaemia in children. Acta Trop. 2009;109:55-60.

17. Oguche S, Okafor HU, Watila I, Meremikwu M, Agomo P, Ogala W, Agomo C, Ntadom G, Banjo O, Okuboyejo T, Ogunrinde G, Odey F, Aina O, Sofola T, Sowunmi A. Efficacy of artemisinin-based combination treatments of uncomplicated falciparum malaria in under-five year-old Nigerian children. Am J Trop Med Hyg. 2014;91:925-35.

18. World Health Organization. Severe falciparum malaria. Transactions of the Royal Society of Tropical Medicine and Hygiene 2000; 94 Supp1: 1-90.

19. World Health Organization. Severe malaria. Trop Med Int Health. 2014; 19(Suppl 1):7-131.

20. Sowunmi A, Akano K, Ayede Al, Ntadom G, Aderoyeje T, Adewoye EO, Fatunmbi B. Clinical illness and outcomes in Nigerian children with late-appearing anaemia after artemisinin-based combination treatments of uncomplicated falciparum malaria. BMC Infect Dis. 2016;16:240.

21. World Health Organization: Assessment and monitoring of antimalarial drug efficacy for the treatment of uncomplicated falciparum malaria. Geneva: world health Organization 2003.

22. Sowunmi A, Akano K, Ayede Al, Ntadom G, Adewoye EO, Fatunmbi B, Aderoyeje T. Therapeutic efficacy and effects of artesunate-amodiaquine and artemether-lumefantrine on malaria-associated anaemia in Nigerian children aged two years and under. Infectious Diseases of Poverty. 2016;5:70.

23. Gbotosho GO, Sowunmi A, Okuboyejo TM, Happi CT, Folarin OO, Michael OS, Adewoye EO. Therapeutic efficacy and effects of artemether-lumefantrine and artesunate amodiaquine co-formulated or co-packaged on malaria-associated anemia in children with uncomplicated Plasmodium falciparum malaria in southwest Nigeria. Am J Trop Med Hyg. 2011;84:813-9.

24. Sowunmi A, Gbotosho GO, Happi CT, Folarin O, Okuboyejo T, Michael O, Fatunmbi B. Use of area under the curve to evaluate the effects of antimalarial drugs on malaria-associated anaemia after treatment. Am J Ther. 2011;18:190-7.

25. Rowland M, Tozer TN. Clinical pharmacokinetics: concept and application. Philadelphia: PA Lea and Ferbiger; 1980

26. Bain BJ, Bates I. Basic haematological techniques. In: Lewis SM, Bain BJ, Bates I, editors. Practical Haematology. 9th ed. Edinburgh: Churchill Living stone 2001; pg. 19-46.

27. Epi Info Version 6. A Word Processing Data Base and Statistics Program for Public Health on IBM-compatible Microcomputers. Centers for Disease Control and Prevention, Atlanta, GA: 1994.

28. SPSS for Windows Release 20.0 (standard version). SPSS Inc., Chicago IL; 2011.
29. Bland JM, Altman DG. Statistical methods for assessing agreement between two methods of clinical measurement. Lancet. 1986;1:307-10.

30. Sowunmi A, Akano K, Ayede Al, Adewoye EO, Ntadom G, Fatunmbi B, Gbotosho GO, Folarin OA, Happi CT. Early rising asexual parasitaemia in Nigerian children following a first dose of artemisinin-based combination treatments of falciparum malaria. BMC Infect Dis. 2017;17:110.

31. Sowunmi A, Akano K, Ntadom G, Ayede Al, Ibironke FO, Aderoyeje T, Adewoye EO, Fatunmbi B, Oguche S, Okafor HU, Watila I, Meremikwu M, Agomo P, Ogala W, Agomo C, Folarin OA, Gbotosho GO, Happi CT. Therapeutic efficacy and effects of artemisinin-based combination treatments on uncomplicated Plasmodium falciparum malaria-associated anaemia in Nigerian children during seven years of adoption as first-line treatments. Infectious Diseases of Poverty. 2017;6:36.

32. Sowunmi A, Balogun T, Gbotosho GO, Happi CT, Adedeji AA, Fehintola FA. Activities of amodiaquine, artesunate, and artesunate-amodiaquine against asexual and sexual stage parasites in falciparum malaria in children. Antimicrob Agents Chemother. 2007;51:1694-9.

33. Sowunmi A, Okuboyejo TM, Gbotosho GO, Happi CT. Early changes in Plasmodium falciparum asexual and sexual populations in children with acute infections following treatment with artemisinin-based combination drugs. Malaria Chemotherapy Control and Elimination. 2012;1 doi:10.4303/ mcce/235498.

34. Robert V, Read AF, Essong J, Tchuinkam T, Mulder B, Verhave JP, Carnevale $P$. Effects of gametocyte sex ratio on infectivity of Plasmodium falciparum to Anopheles gambiae. Trans R Soc Trop Med Hyg. 1996;90:621-4.

35. Sowunmi A, Akano K, Ntadom G, Ayede A, Oguche S, Agomo C, Okafor H, Watila I, Meremikwu M, Ogala W, Agomo P, Adewoye E, Fatunmbi B, Aderoyeje T, Happi C, Gbotosho G, Folarin O. Anaemia following artemisininbased combination treatments of uncomplicated Plasmodium falciparum malaria in children: temporal patterns of haematocrit and the use of uncomplicated hyperparasitaemia as a model for evaluating late-appearing anaemia. Chemotherapy. 2017;62:231-8.

\section{Submit your next manuscript to BioMed Central and we will help you at every step:}

- We accept pre-submission inquiries

- Our selector tool helps you to find the most relevant journal

- We provide round the clock customer support

- Convenient online submission

- Thorough peer review

- Inclusion in PubMed and all major indexing services

- Maximum visibility for your research

Submit your manuscript at www.biomedcentral.com/submit
Biomed Central 